\title{
Prevention and Control of Spontaneous Combustion of Residual Coals in Acid-Soaked Goaf in Gas Drainage Condition
}

\author{
Cunli Qin, ${ }^{1}$ Qiming Huang $\mathbb{D}^{1},{ }^{1}$ Shibin Wang, ${ }^{2}$ Jun Li, ${ }^{1}$ Shuang Ju, ${ }^{2}$ and Gang Wang $\mathbb{D}^{1,3}$ \\ ${ }^{1}$ College of Safety and Environmental Engineering, Shandong University of Science and Technology, Qingdao 266590, China \\ ${ }^{2}$ College of Energy and Mining Engineering, Shandong University of Science and Technology, Qingdao 266590, China \\ ${ }^{3}$ Shandong University of Science and Technology, \\ Mine Disaster Prevention and Control-Ministry of State Key Laboratory Breeding Base, Qingdao 266590, China \\ Correspondence should be addressed to Qiming Huang; skdhuang@163.com
}

Received 20 October 2021; Accepted 31 December 2021; Published 25 February 2022

Academic Editor: ZOU Quanle

Copyright (c) 2022 Cunli Qin et al. This is an open access article distributed under the Creative Commons Attribution License, which permits unrestricted use, distribution, and reproduction in any medium, provided the original work is properly cited.

\begin{abstract}
With the increase of mine mining intensity, the scope of goaf continues to expand, a large amount of coal remains in goaf, and the spontaneous combustion fire of coal is particularly serious. In addition, the spontaneous combustion of coal under the condition of gas mining is not clear. At once, spontaneous combustion can induce gas explosion, resulting in the waste of manpower and material resources, bringing hidden dangers to the mine safety production. In order to prevent and control the fire caused by spontaneous combustion of left coal under the condition of gas mining, in this paper by means of laboratory test, field measurement, and numerical simulation, the law of spontaneous combustion of residual coal under gas mining is studied. The index gas of coal spontaneous combustion was determined by temperature-programmed experimental device. Secondly, the distribution of the stope working face, goaf, and $\mathrm{O}_{2}$ is discussed. It is of great significance to study the spontaneous combustion rule of three belts in goaf under acid leaching condition and then to discuss the best position of injection idling opening and put forward targeted precontrol measures, which is of great significance to guarantee the safety of mine production. The results show that $\mathrm{CO}$ begins to appear when the temperature rises to $40{ }^{\circ} \mathrm{C}$, and its concentration increases exponentially with the increase of coal temperature, which can reflect the degree of coal oxidation in goaf. Therefore, CO should be selected as the indicator gas in the working face. Under the influence of negative drainage pressure, the dangerous area will be enlarged. The optimal drainage volume of high drainage roadway is $90 \mathrm{~m}^{3} / \mathrm{min}$, and the optimal air intake volume of working face is $1400 \mathrm{~m}^{3} / \mathrm{min}$. The area $0-34 \mathrm{~m}$ away from the working face is scattered zone, $34-135 \mathrm{~m}$ away is spontaneous combustion zone, and $135 \mathrm{~m}$ away is asphyxiation zone. When the position of the idler is $50 \mathrm{~m}$ behind the working face, the reduction of the oxidation zone is the largest.
\end{abstract}

\section{Introduction}

As the mining depth of coal mines increases gradually, gas disasters caused by spontaneous combustion in goaf will become more serious, further increasing the risk of gas explosion and leading to graver consequences, especially in goafs with high gas content and spontaneous combustion risk. A gas explosion will rapidly outburst if its conditions meet. However, spontaneous coal combustion develops very slowly, during which gas drainage directly affects the evolution of spontaneous coal combustion in the goaf [1-3]. In addition, due to high mining intensity and great roof-caving height, residual coals and air leakage coexist in the goaf, further worsening spontaneous combustion risk and seriously threatening the safe production of coal $[4,5]$. Furthermore, an increase in goaf temperature enhances spontaneous coal combustion risk, severely restricting the advance of fully mechanized mining technology [6-10]. Therefore, to solve spontaneous coal combustion in goafs, it is of great practical significance to study the prevention and control of spontaneous coal combustion in goaf in the conditions of gas drainage to ensure safe and efficient production in underground mines. 
Scholars and engineers from various countries have started research on the prevention and control of spontaneous combustion of coal under the conditions of gas drainage in the goaf. Observation of the distribution of the three spontaneous combustion zones (heat dissipation zone, oxidation/temperature rising zone, and choking zone) in the goaf to determine the scope of the "three zones" is an important basis for fire prevention and extinguishment of the goaf [11-14]. With the theory of flow field applied to the flow field in the gob, numerical simulation has become an effective approach to study the distribution of gas volume fractions and optimize inert gas injection parameters [15]. Some researchers set such important parameters of gob's permeability, resistance coefficient, gas source term, oxygen dissipation, and the like, as constants, establishing the $2 \mathrm{D}$ model to solve the flow field in the goaf and the optimal technical parameters for preventing fires due to spontaneous coal combustion and further compare the simulated flow field with the actual one in the gob [16]. Relevant scholars have further refined and in-depth studied the relevant theories of spontaneous coal combustion in key areas under gas drainage. Based on the above research results in various periods, they comprehensively applied prevention and control measures for spontaneous combustion of coal in the goaf under gas drainage and made outstanding contributions to the safe and efficient production of the coal industry [17-20]. Jiang et al. [21] established a model for the migration of gas and air mixture in the goaf and carried out a numerical simulation study on the $3 \mathrm{D}$ flow field of a fully mechanized caving mining field. They showed that gas accumulates seriously in the goaf area without drainage and there is a high-risk zone for coexisting gas and spontaneous coal combustion hazard in the possible spontaneous combustion zone. Czech experts Taraba B and Michalec $Z$ [22] aimed at the problem of spontaneous combustion in the goaf of a longwall working face in gas drainage conditions, established a longwall working face model, and studied the impact of the mining speed in the working face on gas emission. They found that there is generally an area suitable for initiation and development of the self-heating process in the goaf. The location and the maximum temperature that can be reached in this area will greatly affect the advancement of the working face. The slower the advancement of the working face, the higher the highest temperature in the area, and the smaller the depth. Yuan et al. [23] applied computational fluid dynamics to analyze different ventilation schemes. They considered the gas flow in the goaf a porous medium laminar flow and simulated the gas flow in the goaf. In addition, they simulated the turbulent flow in the roadway, obtained the contour maps of airflow velocity and velocity vector diagrams, discussed areas prone to spontaneous combustion in the goaf, and optimized the ventilation system of the mine with coexisting disasters of gas and spontaneous coal combustion. Wang et al. [24, 25] developed a new type of composite material to control spontaneous coal combustion in coal mines. The material is a foam gel composed of composite foaming agent (CFA) and high-water absorbent gel (HWAG) and produced via physical and mechanical agitation. It uses the comprehensive properties of the foam and gel to control spontaneous coal combustion in coal mines. The foam gel can effectively block air leakage, prolong the moisturizing time of coal, significantly enhance the cooling effect of water on coal, and effectively reduce the oxidation reaction rate and heating rate of coal to control spontaneous coal combustion in coal mines. Their results have guiding significance for the prevention and control of spontaneous combustion in the goaf similar to the fully mechanized caving working face.

To sum up, under the influence of high ground temperature and acidic soaking water, the spontaneous combustion characteristics of residual coals in the goaf under gas drainage conditions and the distribution of three spontaneous coal combustion zones in the goaf are still unclear. The fire prevention and extinguishing technologies in such mine goafs are still lacking. Therefore, in this study, we took No.204 working face of Gaojiabao Coal Mine as the research object, analyzed $\mathrm{CH}_{4}$ and $\mathrm{O}_{2}$ distribution laws in the working face of the goaf, discussed the influence of drainage volume and air intake on $\mathrm{CH}_{4}$ concentration in the highlevel drainage roadway and $\mathrm{O}_{2}$ concentration in the goaf floor, and comprehensively determined the optimal drainage volume and air intake volume. In view of the characteristics of the acidic soaking water and high ground temperature, we applied the programmed temperature rising experiment to simulate the primary oxidation/secondary oxidation processes of the residual coals in the goaf and determine the index gas. In addition, we adopted numerical simulation techniques to determine the three spontaneous combustion zones in the goaf and the optimal inert gas injection location and carried out on-site engineering practice applications to solve the spontaneous combustion problem of residual coals under gas drainage conditions, with the hope to provide a reference for similar mines.

\section{Overview of the Working Face}

The underground No.204 working face is a V-shaped area located in the west of No.203 working face with $7 \mathrm{~m}$ distance to its clean coal pillar. The specific location is shown in Figure 1. At the east of the No.204 working face is located the No.205 return air trough that is being excavated. The roadway roof elevation of No.204 working face is $+78.122 \mathrm{~m}-+152.338 \mathrm{~m}$. The working face is mined using the fully mechanized inclined longwall top coal caving and retreating method and adopts the fully caving method to manage the roof. It belongs to category 4 and Type II spontaneous combustion coal seam with a spontaneous combustion period of 37 days. The coal mine is identified as a high $\mathrm{CH}_{4}$ mine with a relative gas emission of $1.2 \mathrm{~m}^{3} / t$, absolute gas emission of $7.18 \mathrm{~m}^{3} / \mathrm{min}$, maximum absolute gas emission of $2.7 \mathrm{~m}^{3} / \mathrm{min}$, maximum absolute gushing volume of $0.19 \mathrm{~m}^{3} / \mathrm{min}$, relative emission of carbon dioxide $\left(\mathrm{CO}_{2}\right)$ of $1.53 \mathrm{~m}^{3} / t$, and the absolute $\mathrm{CO}_{2}$ emission of $9.13 \mathrm{~m}^{3} / \mathrm{min}$. 


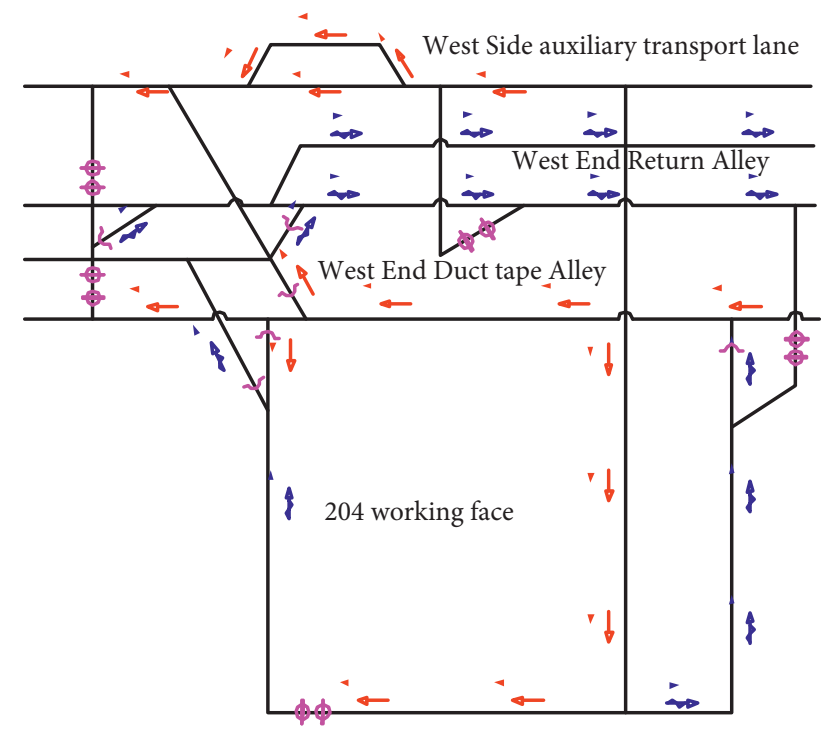

FIGURE 1: Schematic diagram of the specific location of working face.

\section{Programmed Temperature Rising Experiments}

3.1. Programmed Temperature Rising Device. The experiment is carried out with an oxidation simulation experiment system, as shown in Figure 2. The system is composed of a gas preheating subsystem, a heat transfer coal sample tank, a programmed temperature control chamber, a gas collection and analysis device, and a multichannel data collection subsystem. The gas preheating subsystem can provide preheated dry air to the coal sample tank; the programmed temperature control chamber can provide constant temperature, track temperature increasing, or increase temperature based on the predefined program. During the test, the coal sample tank is placed in the programmed temperature control chamber with a constant flow of dry air entering from the bottom of the coal sample tank. The gas at the outlet is collected for subsequent concentration measurement.

The specific experimental steps are as follows.

3.1.1. Filling the Sample. Put $50 \mathrm{~g}$ samples to be tested into the sample tank, and cover a layer of asbestos with a thickness of 2-3 mm evenly above the coal sample, filter the air flow to prevent blocking the gas path, tighten the sample tank with screws at both ends, and seal both ends of the sample tank and the inlet and outlet joint with high temperature resistant raw material belt.

3.1.2. Connecting the Device. Check the connection of power supply, temperature control system, and air supply system to ensure the correct connection of the circuit. The test tube of the coal sample is vertically placed into the main body of the temperature programmed chamber. Adjust the required gas flow, detect the patency of the gas path, and prepare to start the experiment.
3.1.3. Adjusting the Temperature. According to the requirements of the experiment, the temperature control table is used to set the heating program. The change of temperature is another factor that has a great influence on the oxidation process of the original coal samples, and it also has a nonlinear relationship with the coal oxidation rate. The coal oxidation reaction rate is in accordance with the Arrhenius equation; coal molecular structure of surface is active and lively changes along with the change of temperature; the higher the temperature, the faster the reaction speed; studies have shown that the temperature rises every $10^{\circ} \mathrm{C}$. The reaction rate will increase by an order of magnitude. Therefore, the programmed heating rate of each experiment is guaranteed to be the same to enhance the comparability of experimental results. At the same time, in order to ensure that the temperature rise is $1.0^{\circ} \mathrm{C} / \mathrm{min}$ within the precision range of temperature control equipment, analyze the composition and concentration of gas every $10^{\circ} \mathrm{C}$. Turn on the power control switch and program heating switch, and the equipment begins to control heating according to the set value of heating program.

3.2. Experiment Design. Fresh coal samples were collected at the freshly exposed coal wall of the No.204 underground working face in Gaojiabao Coal Mine. A certain amount of coal samples was selected, crushed at room temperature, and sieved. Samples with a particle size of 40-80 mesh $(0.18-0.38 \mathrm{~mm})$ were used in the experiments. They were placed in a tightly sealed container with desiccants on the top to eliminate water. Samples were soaked in different solutions for 5 days and then air-dried at $23{ }^{\circ} \mathrm{C}$ for $24 \mathrm{~h}$. After that, samples were placed at different preoxidation conditions $\left(40{ }^{\circ} \mathrm{C}, 55{ }^{\circ} \mathrm{C}\right.$, and $\left.70{ }^{\circ} \mathrm{C}\right)$ to simulate the primary oxidation/secondary oxidation process of the residual coals in the goaf of No.204 working face. In addition, coal samples were presoaked in the $\mathrm{H}_{2} \mathrm{~S}$-dissolved water solution for 5 days and then air-dried for $24 \mathrm{~h}$ to simulate the affecting process of $\mathrm{H}_{2} \mathrm{~S}$ on the residual coals in the goaf of the working face. Specific experimental conditions are set as shown in Table 1 . Alkanes such as $\mathrm{CO}_{2}$ and $\mathrm{C}_{2} \mathrm{H}_{4}$ will also be produced in the process of temperature programmed experiment, but $\mathrm{CO}_{2}$ will also be produced in the heating process, which does not belong to chemical reaction. Secondly, alkanes such as $\mathrm{C}_{2} \mathrm{H}_{4}$ are produced in a small amount during the experiment, while $\mathrm{CO}$ and $\mathrm{CH}_{4}$ are produced in a large amount and have obvious change rules. Therefore, this paper only discusses the variation of $\mathrm{CO}$ and $\mathrm{CH}_{4}$ gas production under temperature programmed condition.

3.3. Analysis of Experiment Results. Figures 3-6 show the changes in $\mathrm{O}_{2}$ consumption, $\mathrm{CO}$ production, $\mathrm{CO}_{2}$ production, and $\mathrm{CH}_{4}$ production of different pretreated coal samples, respectively. It can be seen from Figure 3 that, at different temperatures, coal samples that have been air-dried for $24 \mathrm{~h}$ after soaking in acidic aqueous solution consume the least $\mathrm{O}_{2}$. At $40-110{ }^{\circ} \mathrm{C}$, the overall changing trend of oxygen consumption of the coal samples is not obvious. At $110-170{ }^{\circ} \mathrm{C}$, the $\mathrm{O}_{2}$ consumption by coal samples is greatly reduced. The $\mathrm{O}_{2}$ 


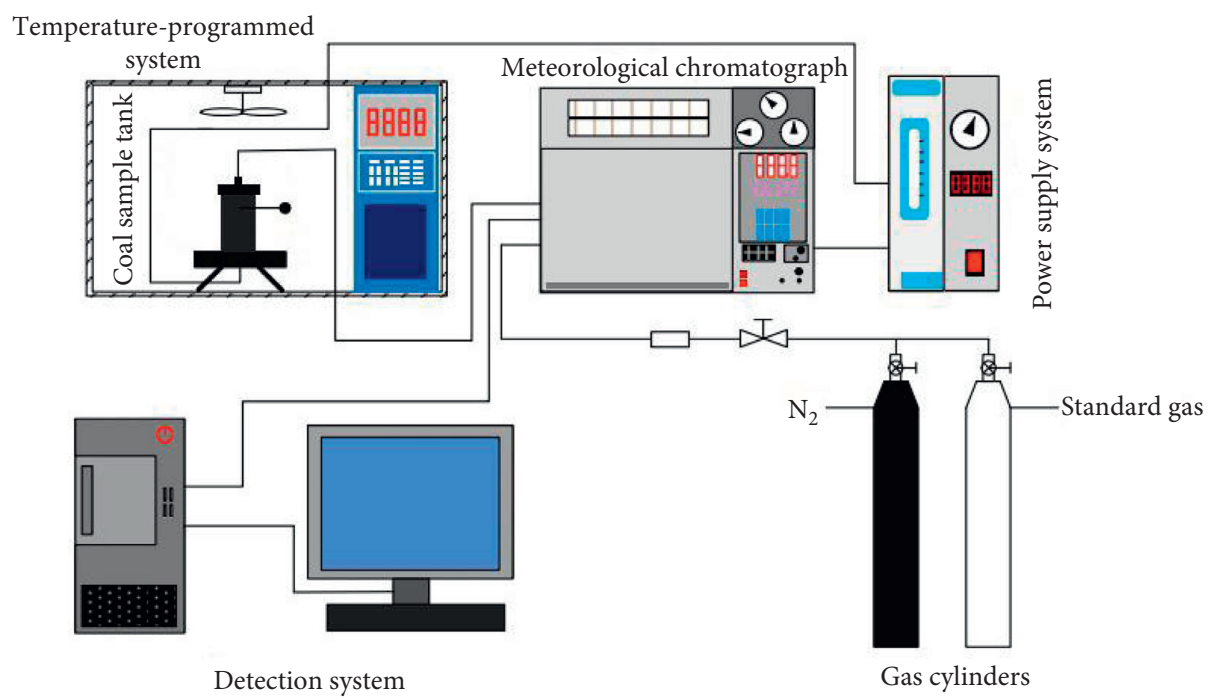

FIgURE 2: Schematics of the programmed temperature rising experiment system of coal samples.

TABle 1: Experimental scheme design conditions setting.

\begin{tabular}{|c|c|c|c|c|}
\hline Serial number & Processing conditions & & For the wind speed & Heating rate \\
\hline 1 & Raw coal & & \multirow{6}{*}{$50 \mathrm{~mL} / \mathrm{min}$} & \multirow{6}{*}{$1.0^{\circ} \mathrm{C} / \mathrm{min}$} \\
\hline 2 & Five-day immersed & Air dry for $24 \mathrm{~h}$ & & \\
\hline 3 & Soak in weakly acidic water & Air dry for $24 \mathrm{~h}$ & & \\
\hline 4 & Preoxidation to $40^{\circ} \mathrm{C}$ & & & \\
\hline 5 & Preoxidation to $55^{\circ} \mathrm{C}$ & & & \\
\hline 6 & Preoxidation to $70^{\circ} \mathrm{C}$ & & & \\
\hline
\end{tabular}

consumption by coal samples preoxidized at $70{ }^{\circ} \mathrm{C}$ shows an overall downward trend. The $\mathrm{O}_{2}$ consumption is $19.02 \mathrm{ppm}$ by $24 \mathrm{~h}$ air-dried coal samples after soaking in acidic aqueous solution, $19.78 \mathrm{ppm}$ by $24 \mathrm{~h}$ air-dried coal samples after soaking in water, $19.88 \mathrm{ppm}$ by coal samples preoxidated at $70{ }^{\circ} \mathrm{C}$, $19.94 \mathrm{ppm}$ by coal samples preoxidated at $55^{\circ} \mathrm{C}, 20.9 \mathrm{ppm}$ by coal samples preoxidated at $40{ }^{\circ} \mathrm{C}$, and $21.05 \mathrm{ppm}$ by raw coal samples. Among them, the $24 \mathrm{~h}$ air-dried coal samples after soaking in acidic aqueous solution consume least $\mathrm{O}_{2}$, while raw coal sample has the greatest risk of spontaneous combustion due to oxidation.

It can be seen from Figure 4 that, at low temperature, that is, $40-80{ }^{\circ} \mathrm{C}$, the $\mathrm{CO}$ production of all coal samples is low, about 40-50 ppm, indicating that coal samples with different pretreatment conditions have relatively small differences at low temperatures. When the temperature rises to $90{ }^{\circ} \mathrm{C}$, samples enter a high temperature stage. As the temperature rises, $\mathrm{CO}$ production begins to change significantly. At 90-120 ${ }^{\circ} \mathrm{C}$, the amount of $\mathrm{CO}$ produced by coal samples begins to diverge although at a slowly increasing rate. At $120-180{ }^{\circ} \mathrm{C}$, the amount of $\mathrm{CO}$ produced by coal samples shows a rapid increase trend. At $180-200{ }^{\circ} \mathrm{C}$, the $\mathrm{CO}$ production of coal samples slows down and reaches the maximum at $200^{\circ} \mathrm{C}$. The $\mathrm{CO}$ production of coal samples under different pretreatment conditions and raw coal samples reaches more than $20,000 \mathrm{ppm}$, which is $400-500$ times the $\mathrm{CO}$ production at the initial temperature. The maximum $\mathrm{CO}$ is produced by the air-dried coal samples weak acidic aqueous solution, reaching $24698 \mathrm{ppm}$. The order of CO

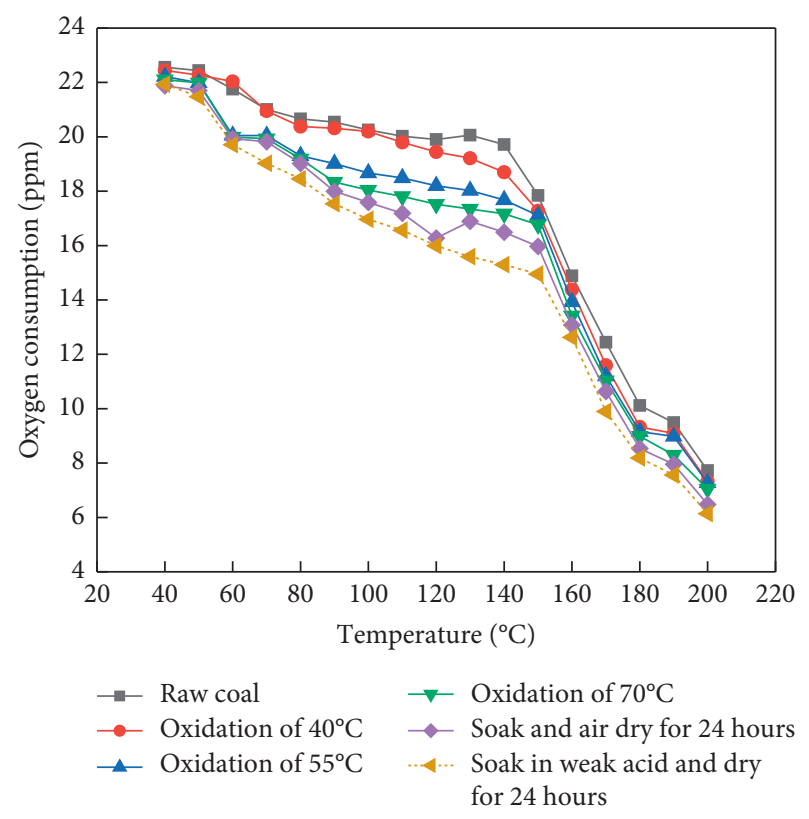

Figure 3: Changes in $\mathrm{O}_{2}$ consumption of different pretreated coal samples.

production is $24 \mathrm{~h}$ air-dried coal samples after soaking in acidic aqueous solution $>24 \mathrm{~h}$ air-dried coal samples after soaking in water $>$ coal samples preoxidated at $70^{\circ} \mathrm{C}>$ coal samples preoxidated at $55^{\circ} \mathrm{C}>$ coal samples preoxidated at $40^{\circ} \mathrm{C}>$ raw coal samples. 


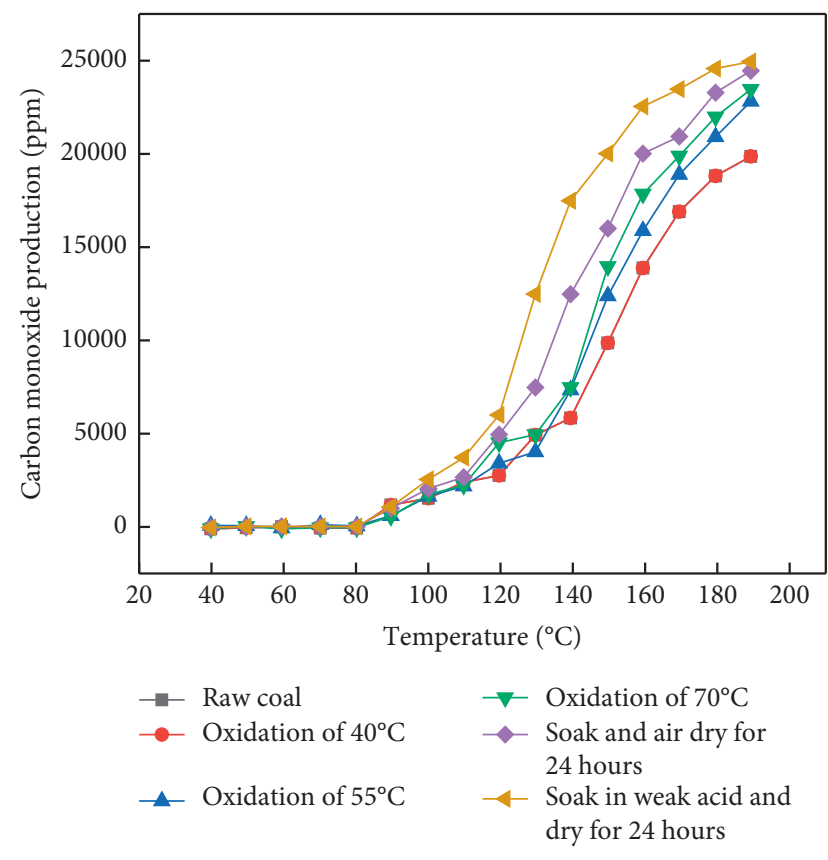

FIGURE 4: CO production of different pretreated coal samples.

It can be seen from Figure 5 that, at low temperature, that is, $40-80^{\circ} \mathrm{C}$, all coal samples produce relatively low $\mathrm{CO}_{2}$, about $400-600 \mathrm{ppm}$, and the difference between different coal samples is small. When the temperature rises to $90^{\circ} \mathrm{C}$, the $\mathrm{CO}_{2}$ production of different coal samples begins to diverge significantly, and the coal samples enter a rapid heating phase. At $90-140^{\circ} \mathrm{C}, \mathrm{CO}_{2}$ production increases at a relatively slow rate. When the temperature rises to $150^{\circ} \mathrm{C}$, the $\mathrm{CO}_{2}$ production starts to rise rapidly until it reaches the maximum at $200^{\circ} \mathrm{C}$. The amount of $\mathrm{CO}_{2}$ reaches $144333 \mathrm{ppm}$ by $24 \mathrm{~h}$ air-dried coal samples after soaking in acidic aqueous solution. At different temperatures, the $\mathrm{CO}_{2}$ production by $24 \mathrm{~h}$ air-dried coal samples after soaking in acidic aqueous solution is always the highest among all samples at different temperatures. The order of $\mathrm{CO}_{2}$ production is $24 \mathrm{~h}$ air-dried coal samples after soaking in acidic aqueous solution $>24 \mathrm{~h}$ air-dried coal samples after soaking in water $>$ coal samples preoxidated at $70^{\circ} \mathrm{C}>$ coal samples preoxidated at $55^{\circ} \mathrm{C}>$ coal samples preoxidated at $40^{\circ} \mathrm{C}>$ raw coal samples.

As can be seen from Figure 6, the amount of $\mathrm{CH}_{4}$ gas produced by coal samples in the process of coal oxidation and spontaneous combustion increases significantly compared with that of raw coal and presents an upward trend. The $\mathrm{CH}_{4}$ production of coal samples soaked in water during the whole process is at the maximum, followed by that soaked in water. The order of $\mathrm{CO}_{2}$ production is as follows: air drying $24 \mathrm{~h}$ for acid-soaked coal sample $>$ air drying $24 \mathrm{~h}$ for soaked coal sample $>$ preoxidation $70{ }^{\circ} \mathrm{C}>$ preoxidation $55^{\circ} \mathrm{C}>$ preoxidation $40^{\circ} \mathrm{C}>$ raw coal.

3.4. Determination of Index Gas of Spontaneous Coal Combustion in an Acidic Environment. Coal spontaneous combustion symbol gas refers to the gas that can mark the spontaneous combustion of coal. The oxidation and thermal

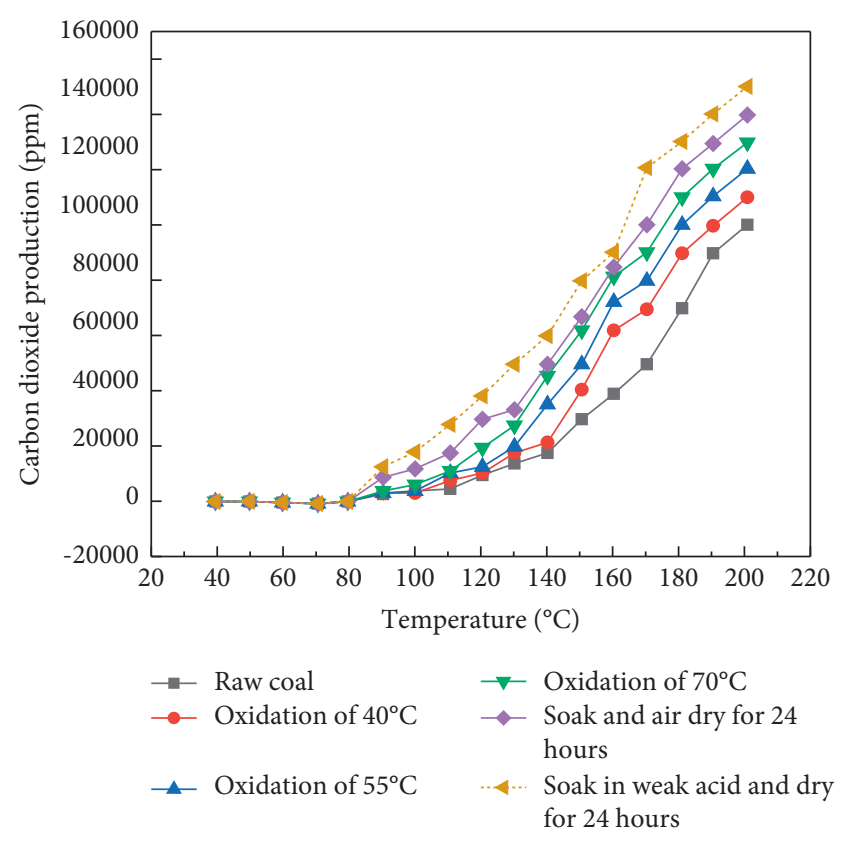

Figure 5: $\mathrm{CO}_{2}$ production of different pretreated coal samples.

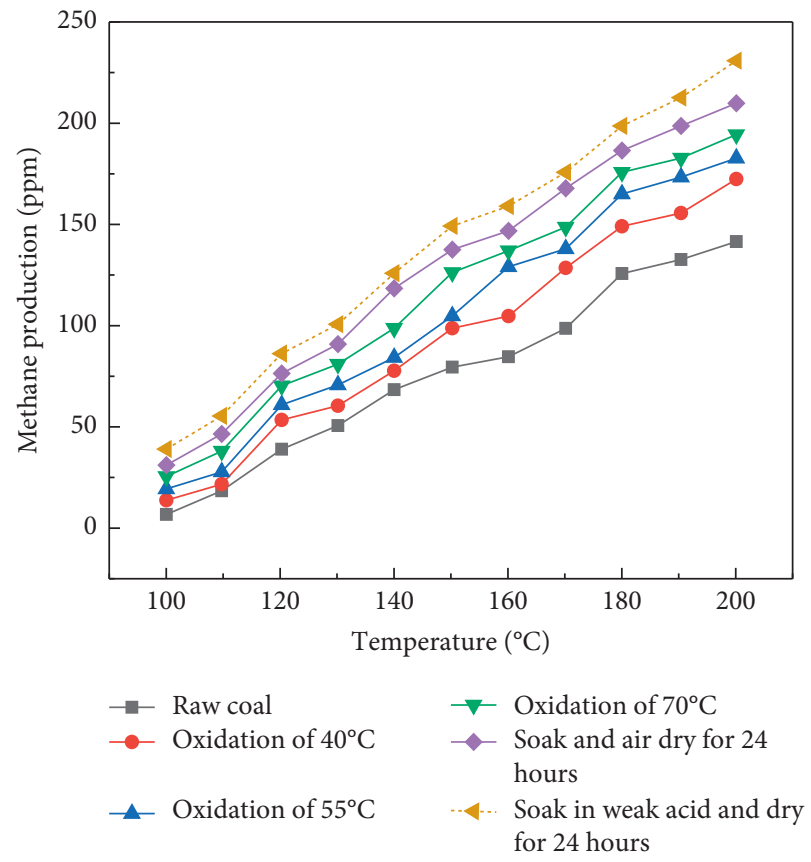

FIgURE 6: $\mathrm{CH}_{4}$ production of different pretreated coal samples.

accumulation of coal will release alkanes, olefin, $\mathrm{CO} 2, \mathrm{CO}$, and other components. The release of gas is affected by time, concentration, type of coal, geological conditions, temperature, oxygen concentration, and other related conditions. Therefore, in order to accurately predict coal spontaneous combustion, a reasonable gas which can reflect the temperature and state of coal spontaneous combustion is selected.

It can be seen from Figure 3 that $\mathrm{CO}$ is present in the atmosphere at $80{ }^{\circ} \mathrm{C}$ although at a relatively low 
concentration. Throughout the entire experiment period, $\mathrm{CO}$ concentration continues to rise with the increase of coal temperature, showing a single increasing exponential relationship. It can be seen from the gas production from coal oxidation that the absolute amount of CO production is the largest among all gas products. The first abrupt $\mathrm{CO}$ concentration change in coal samples occurs at $80{ }^{\circ} \mathrm{C}$, and the second abrupt $\mathrm{CO}$ concentration change occurs at $120{ }^{\circ} \mathrm{C}$.

$\mathrm{CH}_{4}$ production is accompanied by the coal sample temperature rising. At temperatures below the critical temperature, about $70-90^{\circ} \mathrm{C}$, desorption occurs. At temperatures higher than the critical temperature, $\mathrm{CH}_{4}$ concentration increases significantly and exponentially. It can be seen from Figure 5 that $\mathrm{CH}_{4}$ is produced at $100-140^{\circ} \mathrm{C}$ although at relatively low concentration, indicating that the coal samples of Gaojiapu Coal Mine contain a small amount of $\mathrm{CH}_{4}$. Since then, $\mathrm{CH}_{4}$ concentration increases continuously with the increase of coal temperature because the adsorption capacity of the intermolecular Van der Waals force on $\mathrm{CH}_{4}$ gradually weakens with the increase of temperature. Since $\mathrm{CH}_{4}$ is the main component of coal-bed gas, it cannot be used as an index gas for spontaneous coal combustion. The analysis shows that $\mathrm{CO}$ begins to appear when the temperature rises to $40{ }^{\circ} \mathrm{C}$, and its concentration increases exponentially with the increase of coal temperature, which can reflect the degree of coal oxidation in the goaf [26]. The critical temperature of $\mathrm{CH}_{4}$ generation is about $100{ }^{\circ} \mathrm{C}$. Compared with $\mathrm{CO}, \mathrm{CH}_{4}$ shows a significant time difference and temperature difference. Therefore, $\mathrm{CO}$ should be selected as the index gas for No.204 working face.

\section{Determination of the Three Spontaneous Combustion Zones in Goaf}

4.1. Layout of the Measuring Points for the Beam Tube Monitoring System in the Goaf. The gas concentration distribution in the goaf is observed using the buried pipe extraction method. The measurement range is about $200 \mathrm{~m}$ away from the working surface, with measuring points set at an interval of $50 \mathrm{~m}$ to keep 3 measuring points in the air inlet side, return air side, and central area of the goaf. The gas components in the goaf are extracted from each measurement point of the buried pipes and simultaneously tested.

A total of 5 monitoring pipelines are arranged in the transportation trough, return air trough, and the back of the No.204 working face, with one monitoring point set at an interval of $50 \mathrm{~m}$ for each pipeline, as shown in Figure 7. Each monitoring point is equipped with a beam tube device and a gas sample collection device. As the working surface advances, sensors and beam tubes will be buried in the goaf.

Each measuring point is sealed with plastic when no gas is taken out and placed in a hidden place for protection. Because it is too complicated to connect the measuring point with the mine beam tube monitoring system, it is necessary to use a portable air pump for manual sampling and analysis. Every day, a special person is organized to take gas at each measuring point with a balloon (balloon) and send it to the ground chromatographic station for gas chromatographic analysis, instead of using portable instruments. The gas composition of goaf is pumped by buried beam tube for analysis and determination. The beam pipe is laid using 3inch steel tube as a protective sleeve to prevent it from being crushed by falling rock. In order to distinguish different measuring points, identification marks should be made at the exhaust port of the beam tube, the diameter of the beam tube is $8 \mathrm{~mm}$, and the filter probe should be used at the end of the beam tube. Each beam tube is responsible for the gas sample of a measuring point. In order to prevent extrusion, the pipelines laid at the two grooves should be as close to the coal wall as possible, and the probe should be fixed below the coal wall to prevent the probe from being hit during coal mining. The lead is pulled out of a 3 -inch steel tube.

According to the plan, a total of 15 observation points were arranged. Figure 8 shows the observed oxygen concentration distribution at different locations in the goaf. It can be seen from Figure 7 that as the working face advances and the depth of the goaf increases, the oxygen concentration in the goaf shows an overall downward trend. At the depth of $58 \mathrm{~m}$ in the goaf on the return air side, the oxygen concentration drops to $14 \%$, after which the oxygen concentration declines significantly faster, indicating that oxidation of the floating coal in the goaf is more serious. The oxygen concentration on the inlet side decreases more slowly than on the return side and remains at a high level within $82 \mathrm{~m}$ from the working face. The oxygen concentration decreases to about $14 \%$. This is due to the wind pressure difference being greater on the inlet side, resulting in significant air leakage. With the continuous advancement of the working face, the depth of the measuring points buried in the goaf gradually increases. Due to the reduction of air leakage intensity, relatively increased opportunity for the floating coal to react with oxygen, and the effect of oxygen consumption in the coal bed, oxygen concentration gradually decreases [27].

Gas samples are drawn through the buried pipes and boreholes in the mined-out area for testing to investigate the changes in coal parameters in the mined-out area. According to the observation data of the mined-out area, $\mathrm{CO}$ change law in the mined-out area of No.204 working face is obtained, as shown in Figure 9. From the changing trend of $\mathrm{CO}$ concentration contour in the goaf, it can be seen that, with the continuous advancement of the working face, the depth of the measuring point buried in the goaf continues to deepen and $\mathrm{CO}$ concentration changes with an overall trend of increasing before decreasing. When the depth of the measurement point in the goaf on the return air side enters $20 \mathrm{~m}$, CO concentration shows an upward trend, indicating that the floating coals in the goaf begin to be oxidized. The $\mathrm{CO}$ concentration increases rapidly after $60 \mathrm{~m}$, indicating that the floating coal is in the oxidation/temperature rising zone. Therefore, during the advancing process of No.204 working face, $100 \mathrm{~m}$ from the return air side is a key area for fire prevention. In summary, it can be concluded that the distribution of oxygen concentration in the goaf of No.204 working face is relatively wide on the air inlet side, and the oxygen concentration is still maintained at about $14 \%$ at $80 \mathrm{~m}$ from the working face. As the working face continues to advance, the oxygen concentration in the goaf on the inlet 


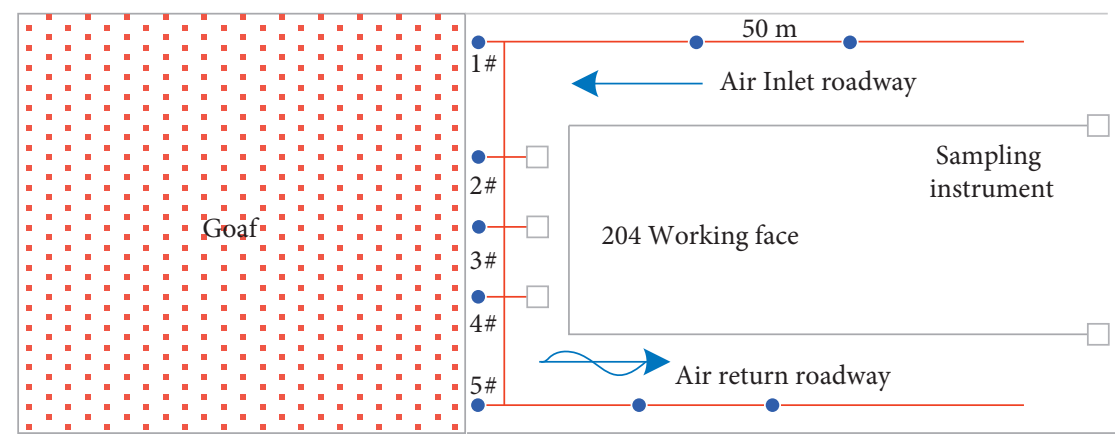

FIgURE 7: Layout of temperature and gas concentration measurement points in No.204 goaf.

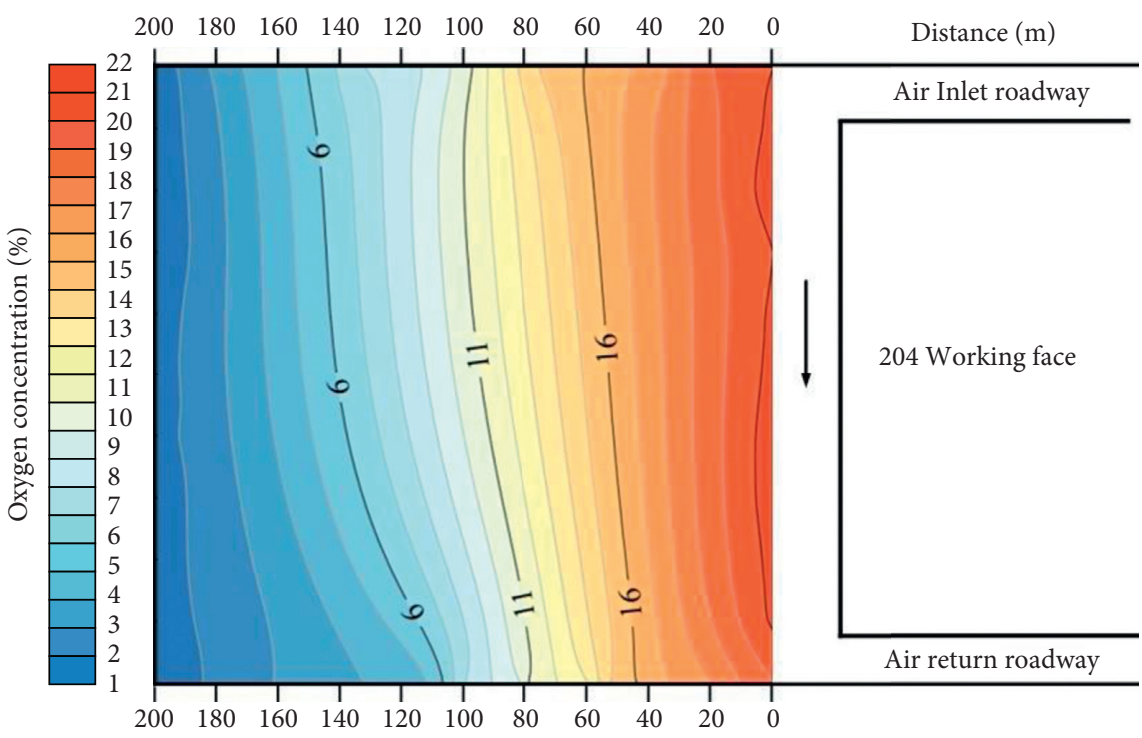

Figure 8: Distribution of $\mathrm{O}_{2}$ concentration in the goaf.

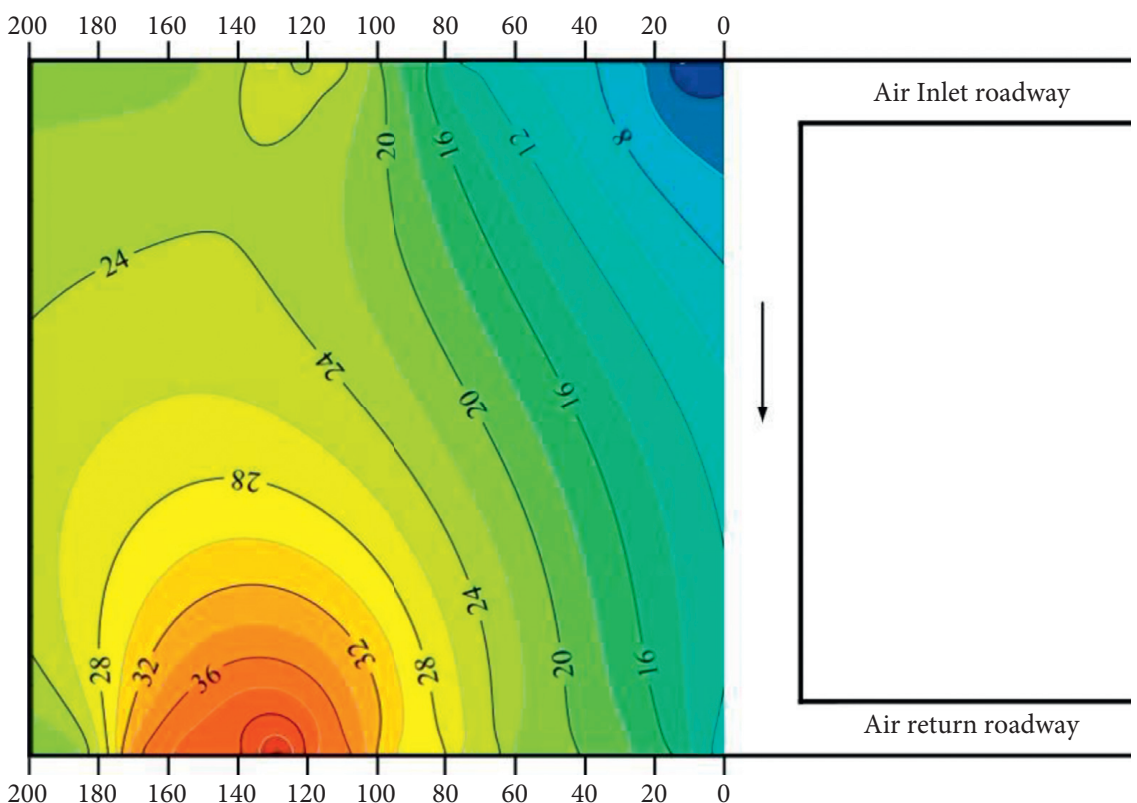

Figure 9: Distribution of $\mathrm{O}_{2}$ and $\mathrm{CO}$ concentration on the inlet side of the goaf. 
side gradually decreases. At $150 \mathrm{~m}$ from the working face, the oxygen concentration drops to about $7 \%$. The distribution range of oxygen concentration on the return air side is relatively shallow. At $20 \mathrm{~m}$ from the working face, the oxygen concentration is maintained at about $18 \%$, and when it is $150 \mathrm{~m}$ deep into the goaf, the oxygen concentration drops to about 5\%. The oxygen concentration distribution in the middle of the goaf area generally decreases from the air inlet side to the return air side. The oxygen concentration at the same buried distance is higher on the inlet side than on the return air side.

4.2. Numerical Simulation of the Three Spontaneous Combustion Zones. 3D mesh model of the fully mechanized goaf in the No.204 working face of Gaojiabao Coal Mine is established. The working face width is $10 \mathrm{~m}$, the air inlet and return roadway is $10 \mathrm{~m}$ long, and the cross section is $5 \mathrm{~m} \times 5 \mathrm{~m}$. The goaf is $26 \mathrm{~m}$ high, $220 \mathrm{~m}$ long, and $200 \mathrm{~m}$ wide. The model is shown in Figure 10.

4.3. "Three-Zone" Simulation Results and Analysis. It can be seen from Figures 11 and 12 that the range of the heat dissipation zone is about $0-34 \mathrm{~m}$ behind the working face. The width of the heat dissipation zone is greater on the side of the air inlet roadway than that the return air roadway of the goaf and the maximum depth of the heat dissipation zone is up to $34 \mathrm{~m}$ behind the working face on the side of the air inlet roadway of the working face and is only $20 \mathrm{~m}$ in the return air roadway.

The distribution range of the heat dissipation zone in the goaf of No.204 working face is within $0-34 \mathrm{~m}$ from the working face in the goaf. Due to the relatively large air leakage at the air inlet side of the goaf, the heat dissipation zone is relatively deep. By contrast, due to the oxygen consumption of the remaining coal on the return air side, the heat dissipation zone is shallow. The choking zone in the deep part of the mined-out area is more than $100-135 \mathrm{~m}$ away behind the working face, as shown in Figure 13. As a result, there is a heat dissipation zone at $0-34 \mathrm{~m}$ from the working face, an oxidation/temperature rising zone at $34-135 \mathrm{~m}$, and a chocking zone beyond $135 \mathrm{~m}$.

\subsection{Mechanism of Spontaneous Combustion of Coal under Gas} Extraction. During the mining of coal seam with high gas and easy spontaneous combustion, the air leakage in goaf is aggravated due to gas extraction, which leads to spontaneous combustion of floating coal in goaf. At the same time, due to the spontaneous combustion of floating coal in goaf, "internal fire wind pressure" is formed locally in goaf, which intensifies the oxygen supply power of floating coal spontaneous combustion in goaf. On the other hand, the spontaneous combustion of floating coal has become the ignition source of gas combustion and explosion, which seriously affects the safe extraction of mine gas. Due to the influence of gas extraction, mining activities around a large area of goaf increase, and harmful gases in a large area of goaf flood into the mine caused by spontaneous combustion or other disasters, resulting in increased risk of personal injury or other production accidents. With the increase of the goaf area, the goaf is divided by different forms of coal pillars such as mining area coal pillar, isolated island coal pillar, corner coal pillar, and so on, and there are many kinds of insufficient mining areas. Because of the thick hard rock strata in the overburden in most areas, there is a hidden danger of mine earthquake caused by sudden instability of overburden in large area [28]. When the mine earthquake occurs, high-pressure airflow rushes out from the goaf and destroys the goaf sealed, threatening personal safety, and it is easy for air leakage to cause natural ignition. With the gradual increase of mining depth, the geothermal gradient increases, the temperature of raw rock increases, the natural starting temperature of coal is high, and the ignition period is shortened. The stress of surrounding rock is large, and the coal body is easy to be crushed and broken. With the increase of mining intensity, the scope of mined-out area is getting larger and larger. No coal pillar mining leads to the connection between mined-out areas, and there are many air leakage channels. In addition, there are many remaining coal in mined-out areas in fully mechanized caving mining [29].

4.5. Influence of High-Level Drainage Parameters on Gas and Spontaneous Coal Combustion. Figure 14 shows the gas concentration distribution at the end of the high-level drainage roadway under different drainage volumes, and Table 2 shows the specific gas drainage data.

It can be seen from Figure 14 and Table 2 that when the drainage volume increases gradually, the gas concentration and scalar quantity both show a trend of first increasing before decreasing. When the drainage volume increases from $80 \mathrm{~m}^{3} / \mathrm{min}$ to $90 \mathrm{~m}^{3} / \mathrm{min}$, the gas drainage range and gas drainage rate of high-level drainage roadways increase, and the gas concentration and scalar quantity also increase. However, with the continuous increase of the drainage volume, the extraction range continues to expand, and the extraction channel is connected to the caving zone of the goaf. The negative pressure pumps make the gas flow from the working face to the high-level drainage roadways, which reduces the gas scalar quantity. Thus, when the drainage volume is $90 \mathrm{~m}^{3} / \mathrm{min}$, the gas drainage volume and gas scalar quantity are moderate, and the gas scalar volume accounts for $70.23 \%$ of the total emission volume.

Figure 15 shows the $\mathrm{O}_{2}$ concentration field of the goaf floor under different drainage conditions. It can be seen from Figure 15 that, with the increase of gas drainage in the high-level drainage roadway, the $\mathrm{O}_{2}$ volume fraction contour moves to the inside of the goaf, indicating that the width of the oxidation/temperature rising zone increases [30]. When the drainage rate is $80 \mathrm{~m}^{3} / \mathrm{min}$, the average width of the oxidation/temperature rising zone in the goaf is $40.24 \mathrm{~m}$, and the maximum width is $50.11 \mathrm{~m}$; when the drainage volume is $90 \mathrm{~m}^{3} / \mathrm{min}$, the average width of the oxidation/ temperature rising zone in the goaf is $63.1 \mathrm{~m}$, and the maximum width is $70.2 \mathrm{~m}$; when the drainage volume reaches $130 \mathrm{~m}^{3} / \mathrm{min}$, the average width of the oxidation/ temperature rising zone in the goaf is $85.1 \mathrm{~m}$, and the 


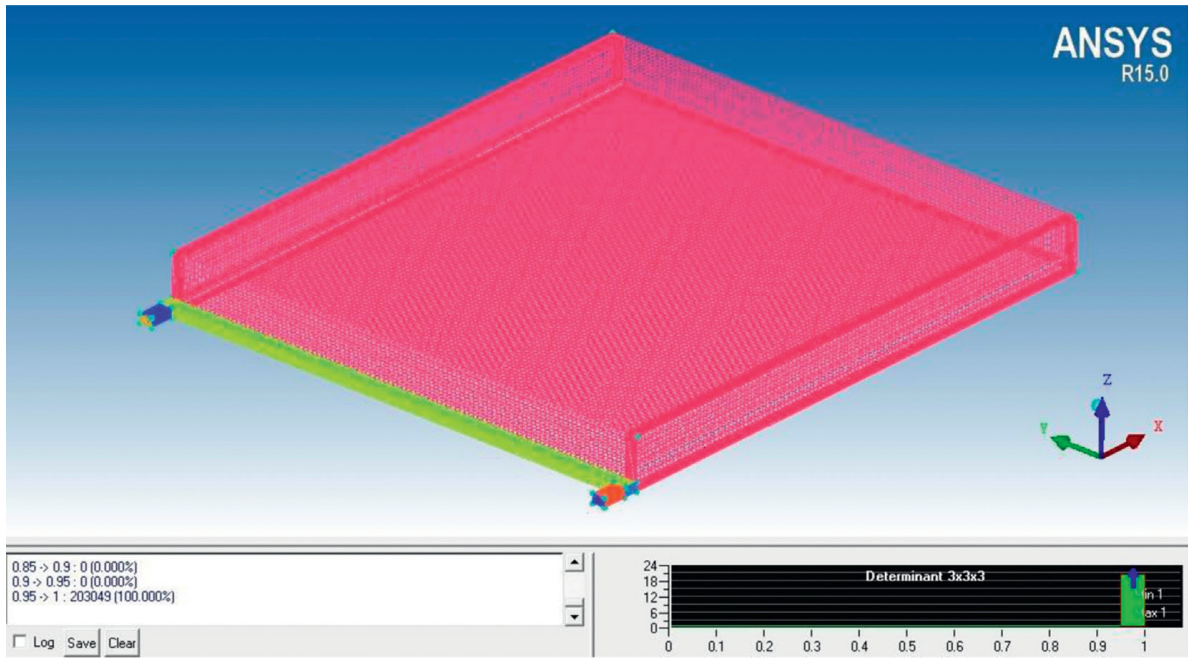

FIGURE 10: 3D goaf model of the working face.
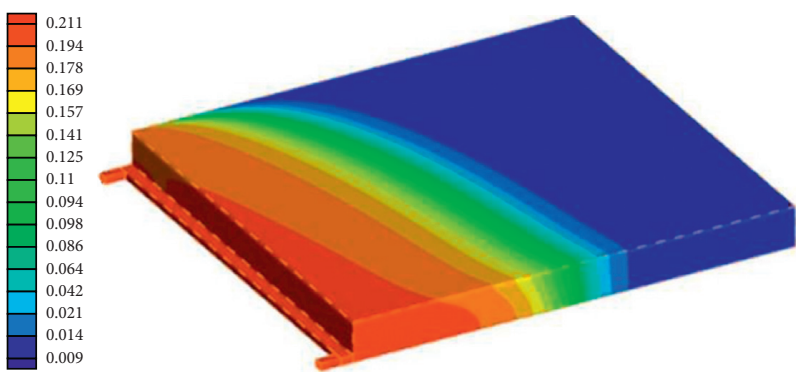

Figure 11: Overall $\mathrm{O}_{2}$ concentration distribution in the goaf.

maximum width reaches $91 \mathrm{~m}$. Overall, with the increase of the gas drainage volume, the width of the oxidation/temperature rising zone in the goaf increases, and the dangerous area will be enlarged under the influence of the negative pressure of the extraction. Comprehensively considering the effect of gas extraction, the optimal gas extraction amount of the high-level drainage roadway is $90 \mathrm{~m}^{3} / \mathrm{min}$.

4.6. Influence of Air Intake on the Three Spontaneous Combustion Zones in the Goaf. Figure 16 shows the field distribution of gas concentration in the high-level drainage roadway area under different air intake conditions. Table 3 shows the specific data. It can be seen from Figure 14 that when the air intake is $1400 \mathrm{~m}^{3} / \mathrm{min}$, the gas concentration and scalar quantity increase correspondingly. The reason is that the increase in air volume causes a slight increase in air leakage, which carries away a large amount of gas in the goaf. When the air volume reaches $1800 \mathrm{~m}^{3} / \mathrm{min}$, the concentration and scalar quantity of gas in the high-level drainage roadway are significantly reduced. The reason is that the air leakage channel of the working face is connected to the drainage channel of the high-level drainage roadway. Under the influence of negative suction pressure, the air that leaked into the working face flows into the high-level drainage roadway through the air leakage fissure, which causes the concentration and scalar quantity of drainage gas to decrease [31].
Figure 16 shows the $\mathrm{O}_{2}$ concentration field of the goaf floor under different air intakes. With the increase of the air intake of the working face, the width of the oxidation/ temperature rising zone on the air inlet side of the goaf increases, reaching $107.3 \mathrm{~m}$ at the maximum, while the width of the oxidation/temperature rising zone on the return air side barely changes. The results show that the increase of the air intake has a greater impact on the width of the oxidation/ temperature rising zone on the air intake side. Therefore, the optimal air intake of the working face is $1400 \mathrm{~m}^{3} / \mathrm{min}$.

4.7. Simulation Results and Analysis of the Influence of Different Inert Gas Injection Positions on the Three Spontaneous Combustion Zones in the Goaf. If the position of the inert gas inlet is too close to the working face, the oxygen concentration in the upper corner will be too low under the influence of air leakage in the goaf. Meanwhile, the inert gas flow route is short, and the effect of reducing the oxygen concentration in the middle and rear of the goaf is not obvious. If the distance between the opening of inert gas injection and the working face is too far, the effect of inert gas inerting oxidation zone in goaf cannot be achieved effectively. In order to determine a reasonable position of compound inerting gas injection and analyze the influence of different inerting positions on nitrogen injection effect, four different positions of inert gas injection port are selected. Since the buried depth of inert gas injection pipeline exceeds $50 \mathrm{~m}$, it is highly likely to be crushed and destroyed by residual coal, so the maximum buried depth of inert gas injection pipeline is set as $60 \mathrm{~m}$. That is, the simulated injection idler is located $30 \mathrm{~m}, 40 \mathrm{~m}, 50 \mathrm{~m}$, and $60 \mathrm{~m}$ behind the working face. Figure 17 shows the numerical simulation results of the three spontaneous combustion zones in the goaf at different injecting sites when setting the injecting flow rate at $600 \mathrm{~m}^{3} / \mathrm{h}$.

It can be seen from Figure 17 that, before injection, the maximum extension depth of the heat dissipation zone on the air inlet side reaches $33 \mathrm{~m}$ behind the working face. When the injection site is $30 \mathrm{~m}$ behind the air inlet side of the 

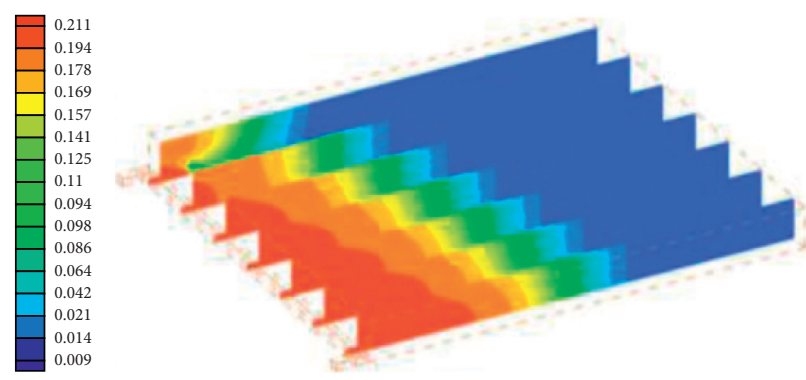

(a)
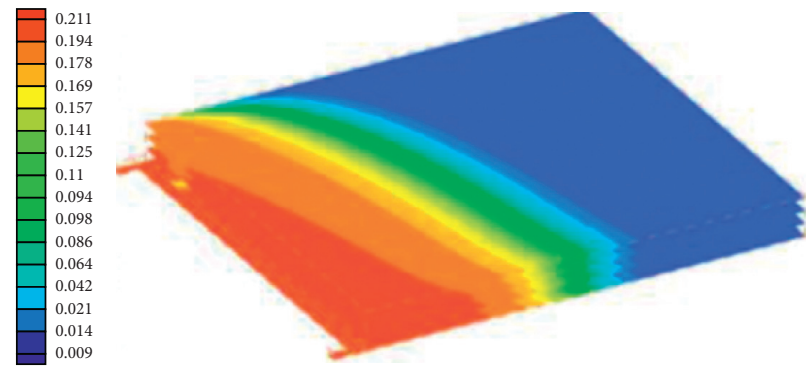

(c)
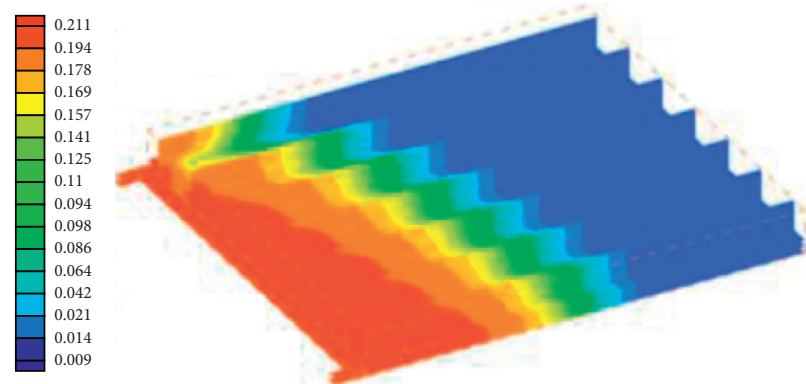

(e)
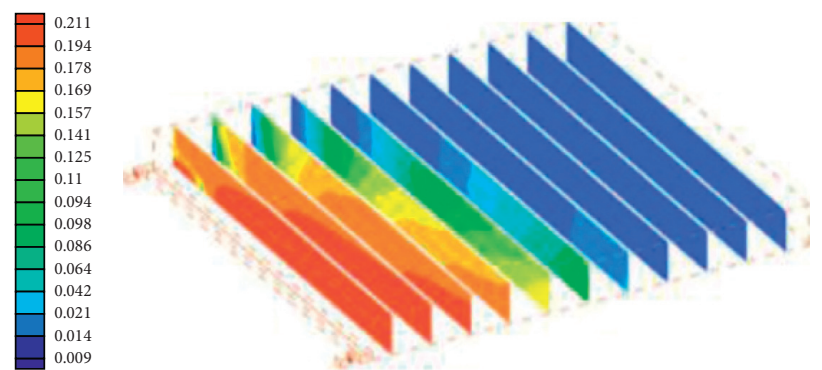

(b)
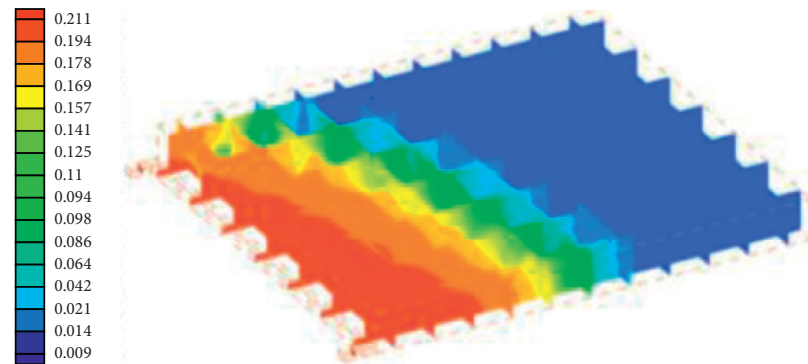

(d)
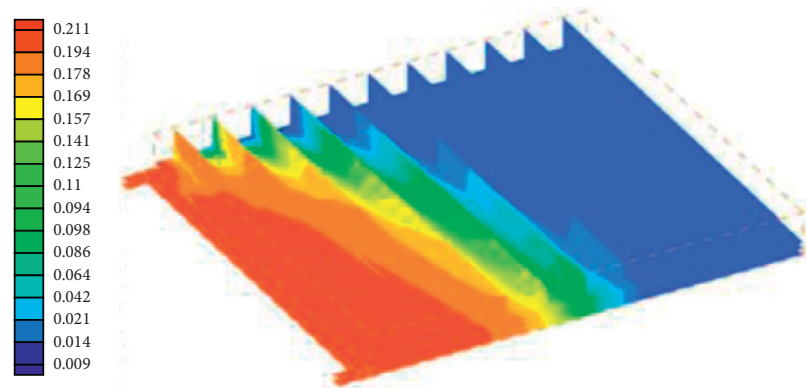

(f)

FIgURE 12: Distribution of $\mathrm{O}_{2}$ concentration in each axis of the goaf. (a) Tangential $\mathrm{O}_{2}$ concentration distribution along the axis $\mathrm{X}$. (b) Tangential $\mathrm{O}_{2}$ concentration distribution along the axis $\mathrm{Y}$. (c) Tangential $\mathrm{O}_{2}$ concentration distribution along the axis $\mathrm{Z}$. (d) Tangential $\mathrm{O}_{2}$ concentration distribution along the axis XY. (e) Tangential $\mathrm{O}_{2}$ concentration distribution along the axis YZ. (f) Tangential O2 concentration distribution along the axis $\mathrm{XZ}$.

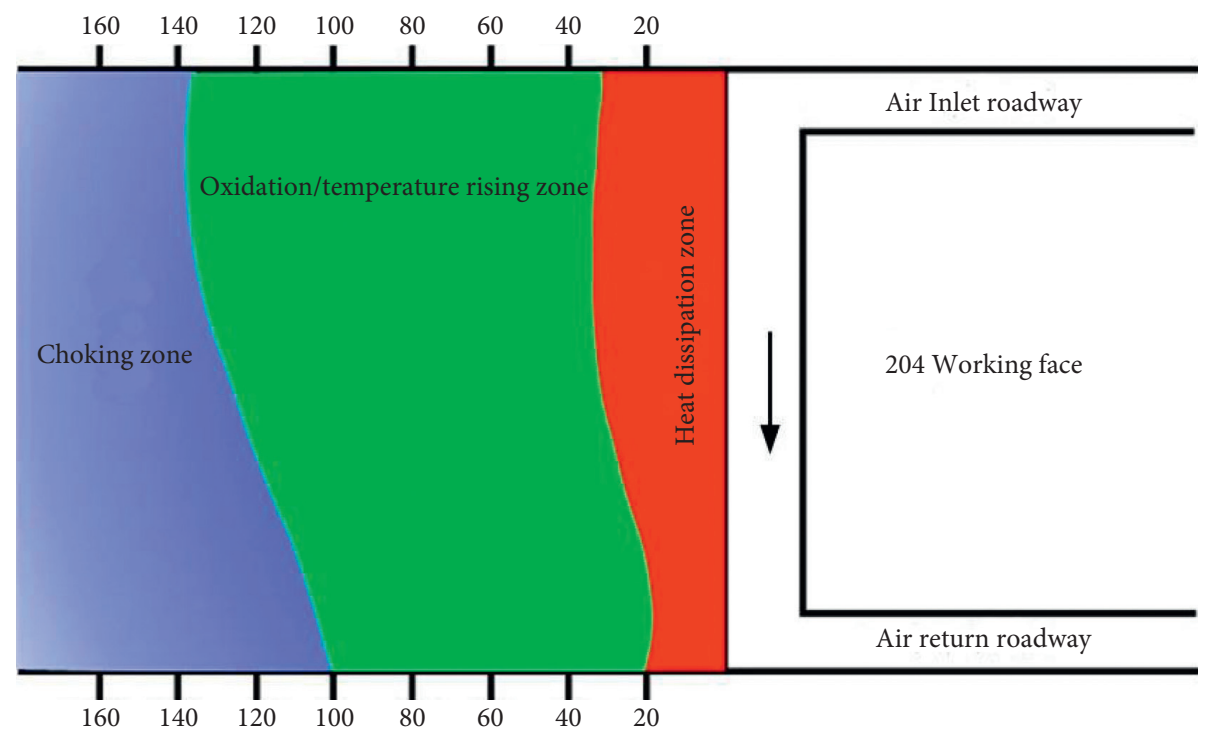

FIGURE 13: Distribution of three spontaneous combustion zones in the goaf. 


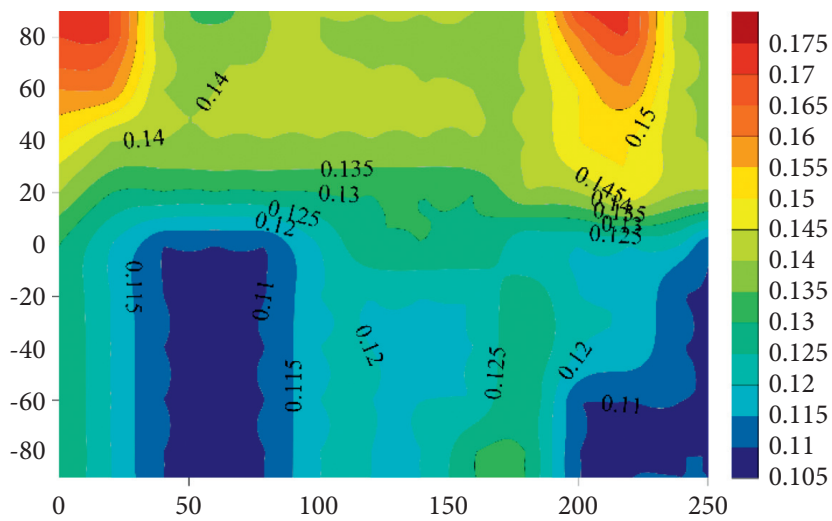

FiguRE 14: $\mathrm{CH}_{4}$ concentration field in high-level drainage roadway under different drainage conditions.

TAвLE 2: Gas drainage data of high drainage roadway under drainage volume conditions.

Gas drainage in high drainage roadway

Drainage volume $\left(\mathrm{m}^{3} \cdot \mathrm{min}^{-1}\right)$ Air intake $\left(\mathrm{m}^{3} \cdot \mathrm{min}^{-1}\right)$ Volume fraction (\%) Scalar quantity $\left(\mathrm{m}^{3} \cdot \mathrm{min}^{-1}\right)$ Proportion of gushing volume

\begin{tabular}{lllll}
\hline 80 & 1400 & 15.3 & 11.30 & 26.63 \\
90 & 1400 & 32.1 & 29.23 & 70.23 \\
110 & 1400 & 16.7 & 16.83 & 41.02 \\
130 & 1400 & 9.4 & 11.61 & 17.41 \\
\hline
\end{tabular}

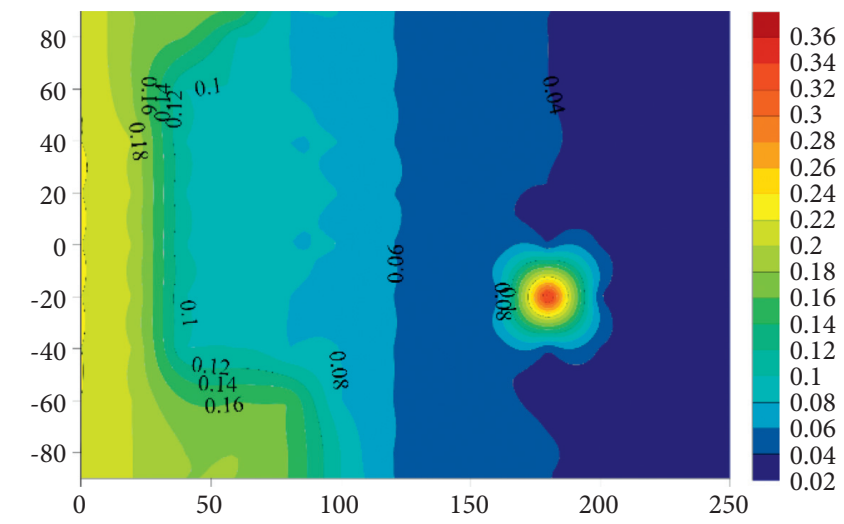

FIgURE 15: $\mathrm{O}_{2}$ concentration field in high-level drainage roadway under different drainage conditions.

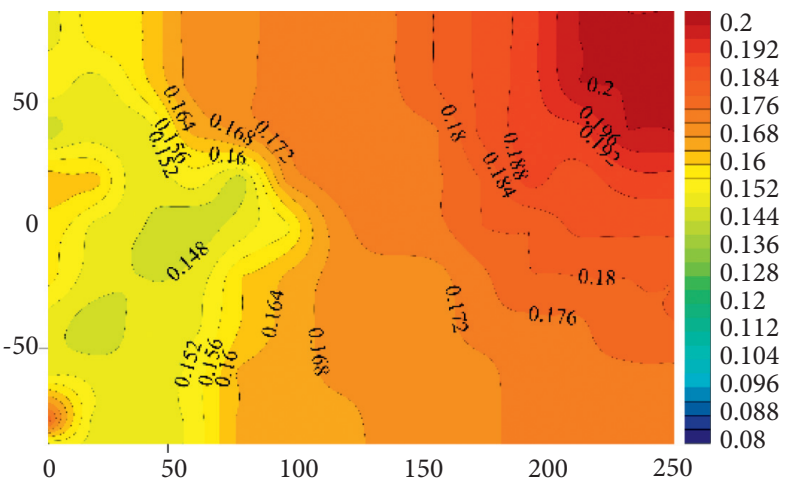

(a)

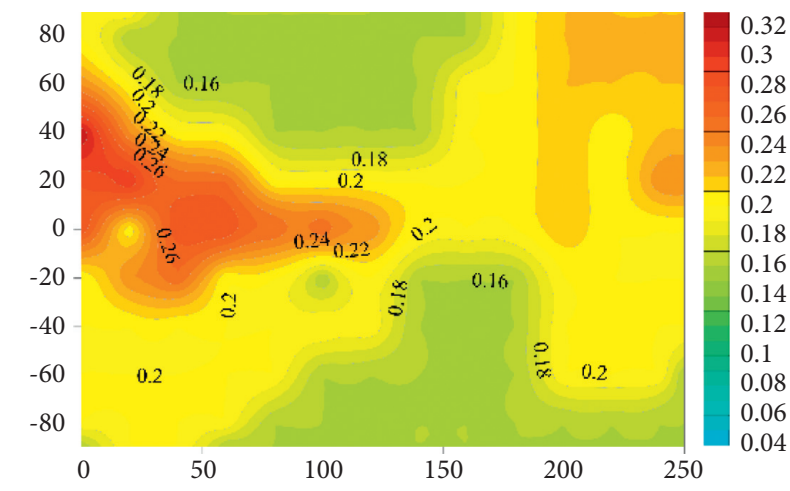

(b)

Figure 16: $\mathrm{O}_{2}$ concentration field in the goaf floor under different air intake conditions. (a) Inlet air volume at $1400 \mathrm{~m}^{3} / \mathrm{min}$ (b) Inlet air volume at $1800 \mathrm{~m}^{3} / \mathrm{min}$. 
TABLE 3: Gas drainage data of high-level drainage roadway under different air intake conditions.

\begin{tabular}{|c|c|c|c|c|}
\hline \multirow[b]{2}{*}{ Air intake $\left(\mathrm{m}^{3} \cdot \mathrm{min}^{-1}\right)$} & \multirow{2}{*}{$\begin{array}{l}\text { Mixing amount } \\
\left(\mathrm{m}^{3} \cdot \min ^{-1}\right)\end{array}$} & \multicolumn{3}{|c|}{ Gas drainage in high drainage roadway } \\
\hline & & Volume fraction (\%) & $\begin{array}{l}\text { Scalar quantity } \\
\left(\mathrm{m}^{3} \cdot \mathrm{min}^{-1}\right)\end{array}$ & Proportion of gushing volume (\%) \\
\hline 1400 & 90 & 32.3 & 29.07 & 69.71 \\
\hline 1800 & 90 & 11.2 & 10.08 & 24.17 \\
\hline
\end{tabular}

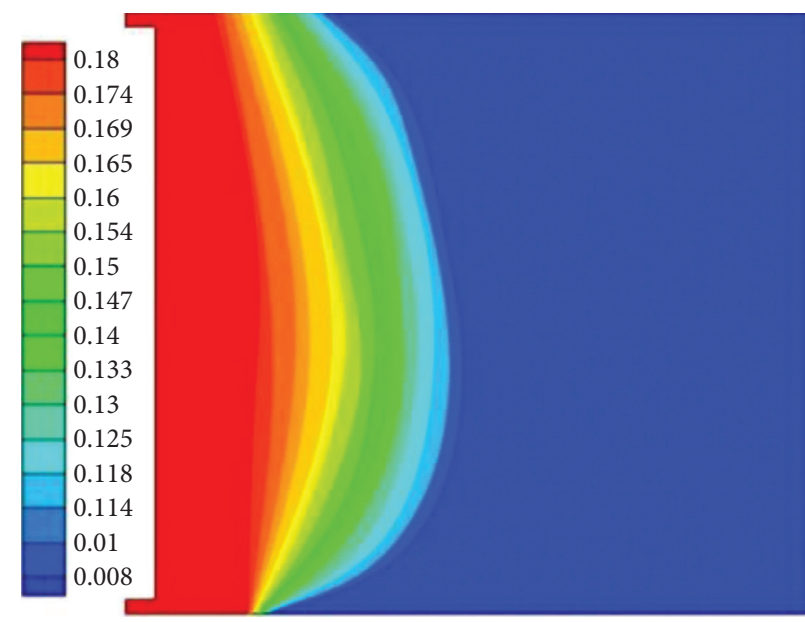

(a)

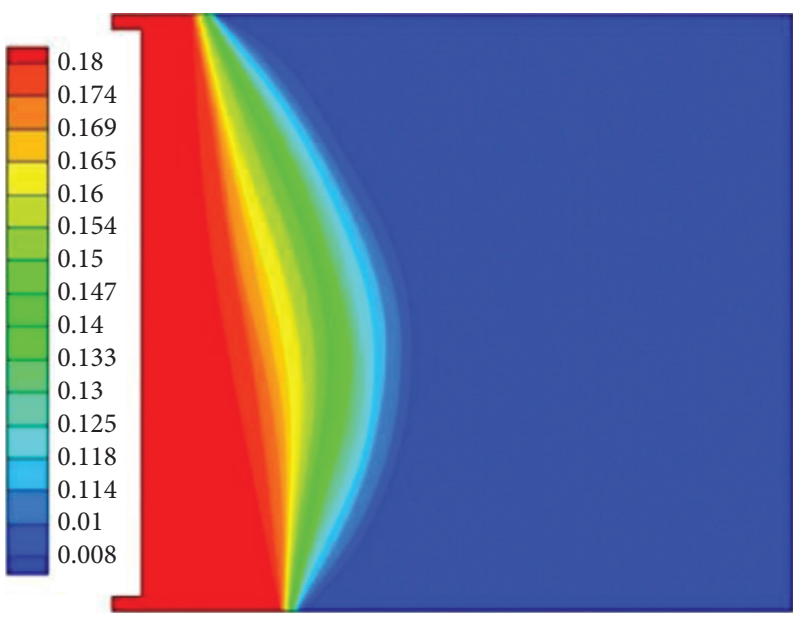

(c)

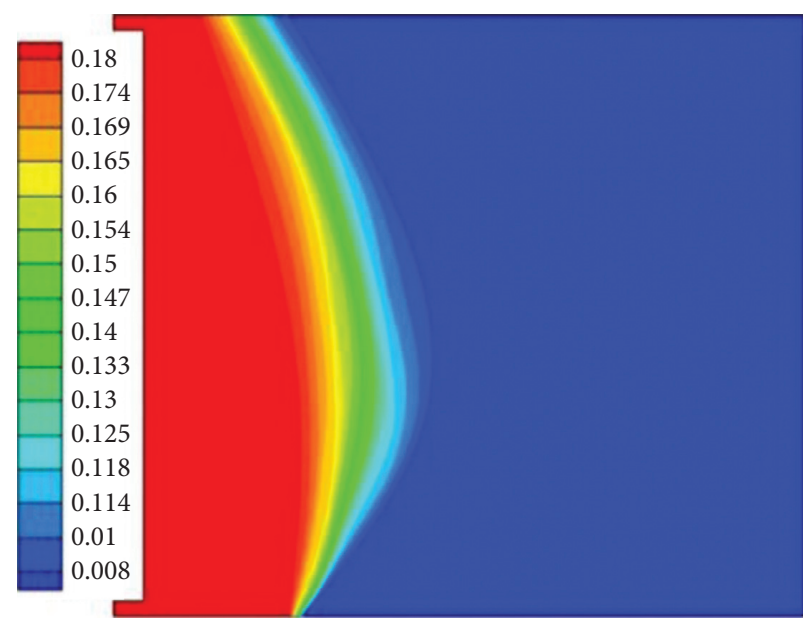

(b)

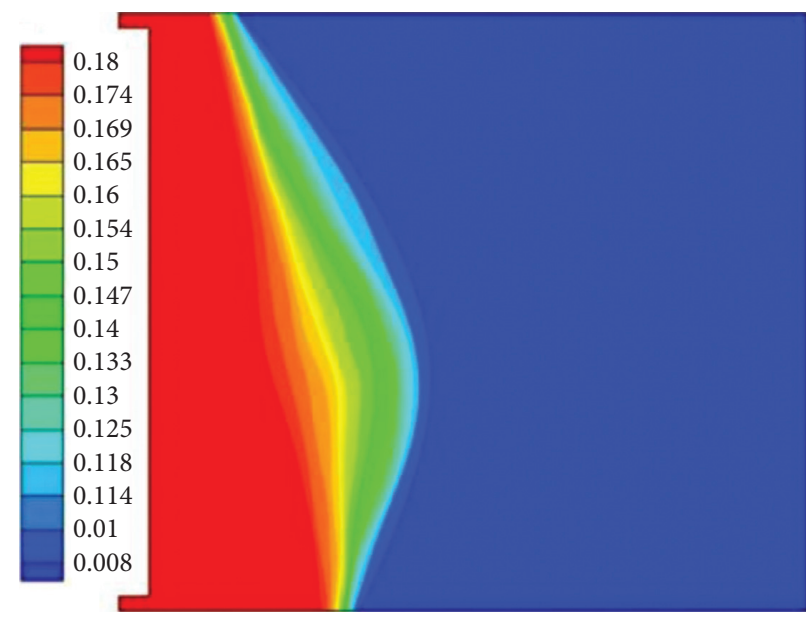

(d)

FIGURE 17: The distribution of $\mathrm{O}_{2}$ concentration in the goaf under different inert gas injection sites. (a) Distribution of $\mathrm{O}_{2}$ concentration in the goaf at $X=30(\mathrm{~m})$. (b) Distribution of $\mathrm{O}_{2}$ concentration in the goaf at $X=40(\mathrm{~m})$. (c) Distribution of $\mathrm{O}_{2}$ concentration in the goaf when $X=50(\mathrm{~m})$. (d) Distribution of $\mathrm{O}_{2}$ concentration in the goaf when $X=60 \mathrm{~m}$.

working face, the heat dissipation zone, oxidation/temperature rising zone, and choking zone converge near the injection site, and the width of oxidation/temperature rising zone behind the goaf significantly declines. After injection at this position, the maximum depth of the oxidation/temperature rising zone in the goaf is $104 \mathrm{~m}$ and reduces about $22.3 \%$. When the injection site is $40 \mathrm{~m}$ behind the working face, the phenomenon of three-zone convergence also occurs at the injection area. Moreover, due to the influence of the injection, the heat dissipation zone near the injection site changes significantly. The maximum depth of the oxidation zone is $95 \mathrm{~m}$, and the maximum width of the oxidation/ temperature rising zone reduces by $39 \mathrm{~m}$ or $29.1 \%$. With the injection depth continuously increasing to make the injection site locate at $50 \mathrm{~m}$ behind the working face, the maximum width of the oxidation/temperature rising zone is $92 \mathrm{~m}$, and the maximum reduction is $31.3 \%$. When the injection site is $60 \mathrm{~m}$ inside the goaf, the inert gas mainly flows to the back of the goaf. The maximum depth of the oxidation/temperature rising zone is $94 \mathrm{~m}$, and the reduction rate is $29.8 \%$. When the injecting site is $50 \mathrm{~m}$ behind the working face, the reduction of the oxidation/temperature rising zone is the largest. It is basically consistent with the on-site measurement results. 
4.8. Influence Law of Spontaneous Combustion of Residual Coal under Gas Drainage Condition in the Goaf. When the drainage volume increases gradually, both gas concentration and scalar quantity show a trend of increasing before decreasing. When the gas drainage range and gas drainage rate of the high-level drainage roadway increase, the gas concentration and scalar quantity also increase. However, with the increase of the extraction volume, the extraction range continues to expand, the extraction channel is connected to the caving zone of the goaf, and the gas is extracted from the working face to the high-level extraction roadway due to the negative pressure, which reduces the gas scalar quantity. In addition, with the increase of gas drainage in the high-level drainage roadway, the $\mathrm{O}_{2}$ volume fraction contour will move to the inner goaf with the increase of the drainage, thereby affecting the width of the oxidation/temperature rising zone.

The change of air intake will affect the change of gas concentration and scalar quantity. This is because increased air volume will lead to a slight increase in air leakage, and a large amount of gas in the goaf is carried away by the air leakage. When the air volume is large enough, the gas concentration and scalar quantity of high-level drainage roadways will decrease slightly, mainly because the air leakage channel of the working face is intersected and connected with the drainage tunnel of the high-level drainage roadway. Under the influence of negative suction pressure, the air leaked from the working face flows into the high-level drainage roadway through the air leakage fissure, leading to decreased gas drainage concentration and scalar quantity. Under different air intakes, the $\mathrm{O}_{2}$ concentration of the goaf floor increases with the air intake of the working face, which in turn affects the width of the oxidation/temperature rising zone.

\section{Spontaneous Combustion Prevention and Control Technology at the Working Face and Its Effectiveness Analysis}

5.1. Prevention and Control Technical Solution. At present, the mine fire prevention and fire extinguishing technologies mainly include grouting, ammonia injection, gel injection, and other conventional measures. In the process of implementation, it is found that due to the influence of geological conditions, the fluidity of grout in goaf is limited, which leads to the poor coverage of goaf. After nitrogen is injected into the goaf, the retention time of nitrogen in the goaf is short due to cracks and air leakage in the surrounding rock. Gel injection or other materials have high cost and complex process and affect production. In recent years, liquid $\mathrm{CO}_{2}$ injection in goaf has a remarkable effect on mine fire prevention and control. Therefore, combined with the actual situation of mine production, this paper analyzes the effect of $\mathrm{CO}_{2}$ fire prevention, in order to provide reference for other mine fire prevention methods.

The direct injection method is adopted, which is to press $\mathrm{CO}_{2}$ into the goaf at the working face along the grouting pipeline using the liquid $\mathrm{CO}_{2}$ self-vaporization pressure. Before the liquid $\mathrm{CO}_{2}$ is injected, the air in the pipeline is vented, and the $\mathrm{CO}_{2}$ concentration reaches $>97 \%$. When injecting liquid $\mathrm{CO}_{2}$, the laying position of the injection pipelines is the same as that of the $\mathrm{N}_{2}$ injection pipelines. The injection site is set at $50 \mathrm{~m}$ in the goaf on the side of the transportation trough, and the injection flow rate of liquid $\mathrm{CO}_{2}$ is $35-45 \mathrm{~m}^{3} / \mathrm{h}$. The injected liquid $\mathrm{CO}_{2}$ flows into the goaf of the working face and is strictly controlled to prevent high-concentration $\mathrm{CO}_{2}$ from flowing into the working face. When the $\mathrm{CO}_{2}$ concentration in the wind flow on the working face reaches $1 \%$, stop pressing.

A set of inhibitor spraying and pressure injection systems are installed in each of the two troughs of No.204 working face, and full-time personnel are arranged to spray the broken coal bodies on the coal walls of the two roadways during the mining process of the working face. The material used for spraying the inhibitor is industrial grade $\mathrm{MgCl}_{2}$, and the concentration of inhibitor solution is calculated using the following equation:

$$
\rho=\frac{T}{C} \times 100 \%=\frac{T}{T+W},
$$

where $\mathrm{C}$ is the amount of inhibitor solution, $\mathrm{kg}$; $T$ is the amount of inhibitor, $\mathrm{kg}$; and $\mathrm{W}$ is the amount of water, $\mathrm{kg}$.

After calculation, the optimal inhibitor concentration is $17 \%$. Therefore, $\mathrm{MgCl}_{2}$ is mixed with water in a ratio of $15 \%$ to $20 \%$. The prepared solution is sprayed to the broken coal walls of the two roadways. The pipeline is $\Phi 25 \mathrm{~mm}$ highpressure hose laid from the rear beam of the support bracket at the return air corner of the working face to the rear beam of the end bracket with a three-way stop valve installed every $20 \mathrm{~m}$. The pipeline outlet is connected to the inhibitor injection pump and the pipeline inlet is connected to a $\varphi 13 \mathrm{~mm}$ hose and spray gun.

5.2. Engineering Practice Effect Analysis. As shown in Figure 18, after implementing the strengthened fire prevention measures during the mining cease period at No.204 working face, $\mathrm{CO}$ concentration at each measurement point gradually decreases to $11 \mathrm{ppm}$ at the corner of the return air, to $4 \mathrm{ppm}$ at the corner of the inlet air, and to a normal value at the No.204 working face. As shown in Figure 19, the gas concentration in the upper corner and the return air lane showed an obvious decreasing trend. During the mining, the gas concentration in each area of the working face is within a reasonable range, and the gas concentration in the upper corner is always stable at $0.1 \%-0.5 \%$, which is within a reasonable range, indicating the measures have achieved a good application effect.

\section{Conclusion}

The absolute amount of $\mathrm{CO}$ produced is the largest among all gas products. The temperature of $\mathrm{CO}$ concentration in coal sample was $80{ }^{\circ} \mathrm{C}$ for the first time and $120{ }^{\circ} \mathrm{C}$ for the second time. When the temperature of coal sample is about 


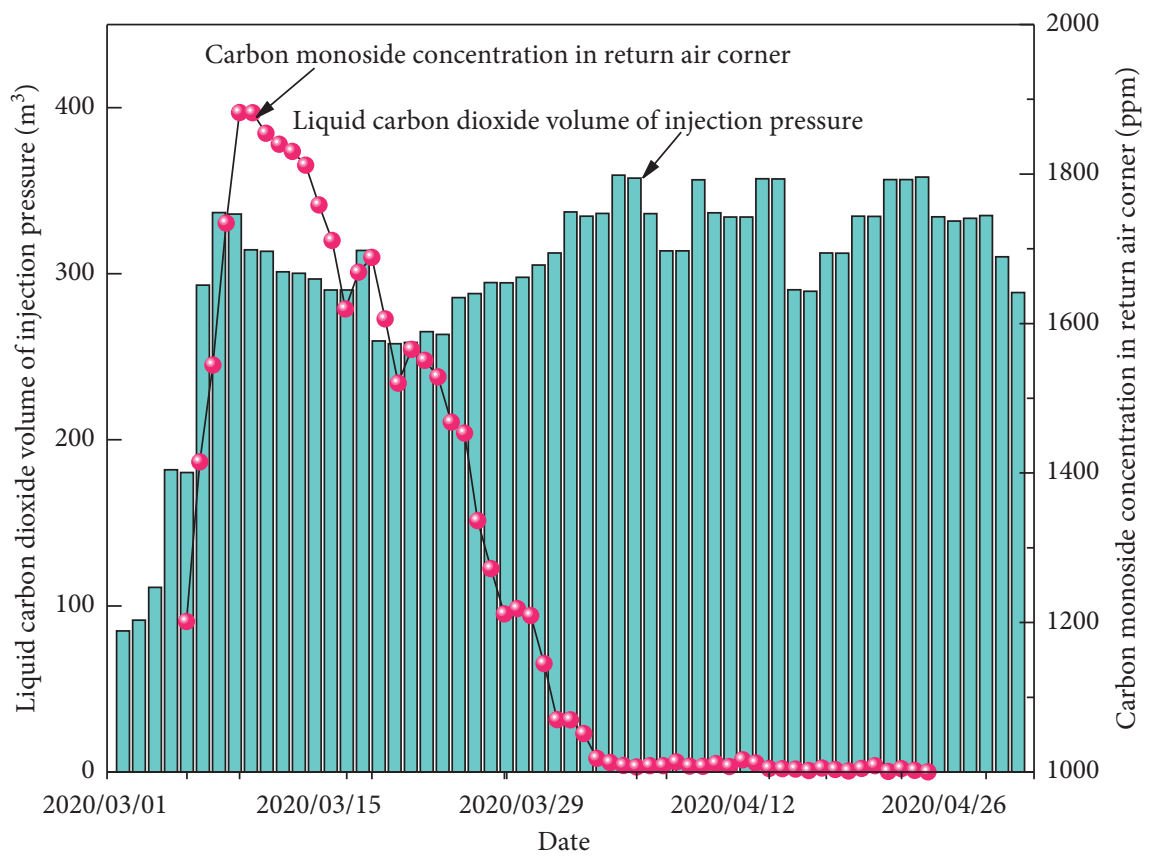

FIGURE 18: Distribution of CO concentration in the goaf under different inert gas injection sites.

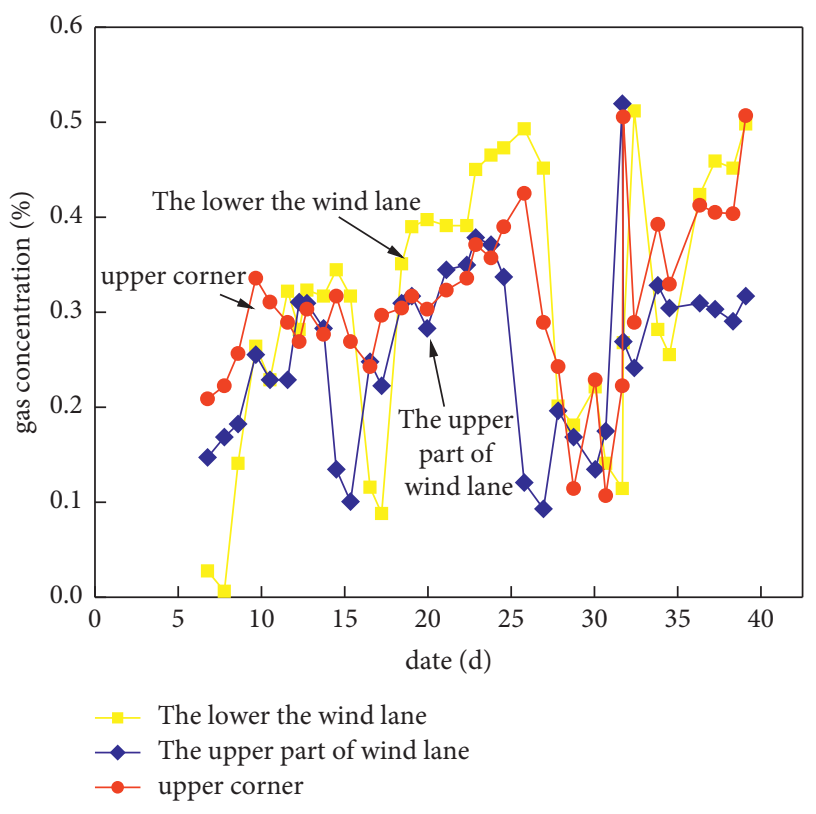

Figure 19: Gas extraction situation.

$70-90{ }^{\circ} \mathrm{C}$, the desorption phenomenon occurs. When the temperature exceeds the critical temperature, the gas concentration increases obviously, showing an exponential relationship. $\mathrm{CH}_{4}$ gas is produced when the temperature of coal is $100-140^{\circ} \mathrm{C}$, but its concentration is relatively small. Since then, the concentration of $\mathrm{CH}_{4}$ gas increases continuously with the rise of coal temperature, because the adsorption capacity of intermolecular Van der Waals force on $\mathrm{CH}_{4}$ decreases gradually with the rise of temperature.
When the temperature rises to $40{ }^{\circ} \mathrm{C}, \mathrm{CO}$ begins to appear, and its concentration increases exponentially with the increase of coal temperature. The critical temperature of $\mathrm{CH}_{4}$ is about $100{ }^{\circ} \mathrm{C}$. Compared with $\mathrm{CO}$ gas, $\mathrm{CH}_{4}$ has significant time difference and temperature difference. Therefore, $\mathrm{CO}$ should be selected as the indicator gas in the working face.

With the increase of pumping amount, the width of oxidation heating zone in goaf increases, and the dangerous zone will be enlarged under the influence of negative pumping pressure. The optimal pumping volume of highlevel roadway is $90 \mathrm{~m}^{3} / \mathrm{min}$. With the increase of air inlet volume, the width of oxidation heating zone on the inlet side of goaf increases obviously, while the width of oxidation heating zone on the return side of goaf changes very little. The optimal air inlet volume of working face is $1400 \mathrm{~m}^{3} / \mathrm{min}$

The area $0-34 \mathrm{~m}$ away from the working face is scattered zone, 34-135 $\mathrm{m}$ away is spontaneous combustion zone, and $135 \mathrm{~m}$ away is asphyxiation zone. The oxidation zone has the largest reduction range, and the $\mathrm{CO}$ concentration at the corner of the return air and the corner of the inlet air decreases to 11 PPM and 4 PPM, and the CO gas concentration at the 204 working face decreases to the normal value. It proves that the measures adopted to strengthen the fire extinguishing measures are effective, and good application effect has been achieved.

\section{Data Availability}

The raw/processed data required to reproduce these findings cannot be shared at this time as the data also form part of an ongoing study. 


\section{Conflicts of Interest}

The authors declare that they have no conflicts of interest.

\section{References}

[1] G.. Zhou, Mechanism of Using Liquid-State Carbon Dioxide against Fire and its Key Techniques Development and Application, Xi'an University of Science and Technology, Xi'an,China, 2019.

[2] G.. Li, Study on Spontaneous Coal Combustion Law and Key Prevention Technology in Goaf under Gas Drainage Condition, Shandong University of Science and Technology, Qingdao,China, 2019.

[3] X.. Huang, Research on Fire Control Technology of Residual Pillar Mining with Spontaneous Combustion in Mine, China University of Mining and Technology, Beijing,China, 2015.

[4] Y.. Wang, Research on Prevention and Treatment Technology of Spontaneous Combustion in Goaf of Close-Distance Coal Seams, China University of Mining and Technology, Beijing,China, 2015.

[5] H. Fujitsuka, R. Ashida, M. Kawase, and K. Miura, "Examination of low-temperature oxidation of low-rank coals, aiming at understanding their self-ignition tendency," Energy and Fuels, vol. 28, no. 4, pp. 2402-2407, 2014.

[6] Y. Song, B. Jiang, and M. Qu, "Molecular dynamic simulation of self- and transport diffusion for $\mathrm{CO}_{2} / \mathrm{CH}_{4} / \mathrm{N}_{2}$ in low-rank coal vitrinite," Energy and Fuels, vol. 32, no. 3, pp. 3085-3096, 2018.

[7] Y. Song, B. Jiang, J. P. Mathews, G. Yan, and F. Li, "Structural transformations and hydrocarbon generation of low-rank coal (vitrinite) during slow heating pyrolysis," Fuel Processing Technology, vol. 167, no. 4, pp. 535-544, 2017.

[8] S. Sun, P. He, G. Wang et al., "Shape characterization methods of irregular cavity using Fourier analysis in tunnel," Mathematics and Computers in Simulation, vol. 187, pp. 191-214, 2021.

[9] R.-L. Du, K. Wu, D.-A. Xu, C.-Y. Chao, L. Zhang, and X.-D. Du, "A modified Arrhenius equation to predict the reaction rate constant of Anyuan pulverized-coal pyrolysis at different heating rates," Fuel Processing Technology, vol. 148, pp. 295-301, 2016.

[10] J. Li, Q. Huang, G. Wang, E. Wang, S. Ju, and C. Qin, "Experimental study of effect of slickwater fracturing on coal pore structure and methane adsorption," Energy, vol. 239, Article ID 122421, 2022.

[11] T. Xu, D. Wang, H. Xin, and X. Qi, "Experimental study on the temperature rising characteristic of spontaneous combustion of coal," Journal of Mining \& Safety Engineering, vol. 29, no. 4, pp. 575-580, 2012.

[12] J. Deng, J. Zhao, Y. Zhang, and R. Geng, "Study on spontaneous coal combustion characteristic temperature of growth rate analysis," Procedia Engineering, vol. 84, pp. 796-805, 2014.

[13] X. Chen, X. Yi, and J. Deng, "Experiment study of characteristic self-heating intensity of coal," Journal of China Coal Society, vol. 5, p. 017, 2015.

[14] J. Deng, J. Zhao, and Y. Zhang, "Micro-characteristics of spontaneous combustion of second oxidation with different rank coals," Journal of China Coal Society, vol. 41, no. 5, pp. 1167-1172, 2016.

[15] H. Usui and S. Ishikawa, "The evaluation of spontaneous combustion characteristics and properties of raw and upgraded Indonesian low rank coals," Coal Preparation, vol. 22, pp. 81-91, 2002.

[16] J. Deng, Q. Li, X. Yang, and S. Min, "Experimental study on the thermal properties of coal during pyrolysis, oxidation, and re-oxidation," Applied Thermal Engineering, vol. 22, pp. 81-91, 2016.
[17] X. Li, Experimental Study on Characteristic Parameters of Spontaneous Combustion of Soaked and Air-Dried Coal, China University of Mining and Technology, Xuzhou,China, 2014.

[18] T. Jia, S. Wang, and H. Yu, "Experiments on the precipitation and oxidation characteristics of alkanes in spontaneous combustion of coal," Journal of Liaoning Technical University, vol. 31, no. 06, pp. 830-833, 2012.

[19] M. Wang, Q. Li, and F. Meng, "Study on comprehensive fire prevention technology for goaf during the stopping period of medium-and-thick coal seam," China Coal, vol. 47, no. 07, pp. 39-45, 2021.

[20] K. Jiang, Y. Wang, and G. Reng, "Study on the optimization simulation and application of technical parameters of $\mathrm{CO}_{2}$ injection for fire prevention in goaf in 8059 working face of Yaoqiao Coal Mine," Mining Safety \& Environmental Protection, vol. 48, no. 03, pp. 74-78+84, 2021.

[21] J. Si, J. Zhang, and G. Chen, "Experimental study on the coexistent characteristics of both gas drainage and spontaneous coal combustion in goaf," Journal of North China Institute of Science and Technology, vol. 16, no. 04, pp. 1-5, 2019.

[22] W. Cui, Q. Meng, Q. Feng, L. Zhou, Y. Cui, and W. Li, "Occurrence and release of cadmium, chromium, and lead from stone coal combustion," International Journal of Coal Science \& Technology, vol. 06, no. 04, pp. 586-594, 2019.

[23] Z. Li, H. Jia, Q. Bi, Y. Wen, and D. Wang, "Study on relevance between gas source strength and spontaneous combustion in goaf of top coal caving," Journal of China Coal Society, vol. 37, no. s1, pp. 120-125, 2012.

[24] M. Więckowski, N. Howaniec, and S. Adam, "Effect of flow rates of gases flowing through a coal bed during coal heating and cooling on concentrations of gases emitted and fire hazard assessment," International Journal of Coal Science \& Technology, vol. 07, no. 01, pp. 107-121, 2020.

[25] B. Taraba and Z. Michalec, "Effect of longwall face advance rate on spontaneous heating process in the gob area - CFD modelling," Fuel, vol. 90, no. 8, pp. 2790-2797, 2011.

[26] J. Li, Q. Huang, G. Wang, and E. Wang, "Influence of active water on gas sorption and pore structure of coal," Fuel, vol. 239, Article ID 122400, 2022.

[27] C. Fan, L. Yang, G. Wang, Q. Huang, X. Fu, and H. Wen, "Investigation on coal skeleton deformation in $\mathrm{CO}_{2}$ injection enhanced $\mathrm{CH}_{4}$ drainage from underground coal seam," Frontiers of Earth Science, vol. 09, pp. 01-11, 2021.

[28] C. Fan, S. Li, D. Elsworth, J. Han, and Z. Yang, "Experimental investigation on dynamic strength and energy dissipation characteristics of gas outburst prone coal," Energy Scienced Engineering, vol. 08, no. 04, pp. 1015-1028, 2020.

[29] Z. Zhou, Z. Li, C. Gao et al., "Peridynamic micro-elastoplastic constitutive model and its application in the failure analysis of rock masses," Computers and Geotechnics, vol. 132, 2021.

[30] A. Liu, S. Liu, G. Wang, and D. Elsworth, "Continuous compaction and permeability evolution in longwall gob materials," Rock Mechanics and Rock Engineering, vol. 53, no. 12, pp. 5489-5510, 2020.

[31] A. Liu, S. Liu, G. Wang, and D. Elsworth, "Predicting fugitive gas emissions from gob-to-face in longwall coal mines: coupled analytical and numerical modeling," International Journal of Heat and Mass Transfer, vol. 150, pp. 119-392, 2020. 